\title{
Las relaciones entre Chupícuaro y el Centro de México durante el Preclásico reciente. Una crítica de las interpretaciones arqueológicas
}

\section{Véronique Darras}

\section{(2) OpenEdition}

\section{Journals}

Edición electrónica

URL: https://journals.openedition.org/jsa/3105

DOI: $10.4000 /$ jsa. 3105

ISSN: $1957-7842$

Editor

Société des américanistes

Edición impresa

Fecha de publicación: 1 junio 2006

Paginación: 69-110

ISSN: 0037-9174

\section{Referencia electrónica}

Véronique Darras, «Las relaciones entre Chupícuaro y el Centro de México durante el Preclásico reciente. Una crítica de las interpretaciones arqueológicas», Journal de la Société des américanistes [En línea], 92-1 et 2 | 2006, Publicado el 15 enero 2012, consultado el 03 septiembre 2022. URL: http:// journals.openedition.org/jsa/3105; DOI: https://doi.org/10.4000/jsa.3105 


\title{
LAS RELACIONES ENTRE CHUPÍCUARO Y EL CENTRO DE MÉXICO DURANTE EL PRECLÁSICO RECIENTE. UNA CRÍTICA DE LAS INTERPRETACIONES ARQUEOLÓGICAS
}

\author{
Véronique DARRAS *
}

\begin{abstract}
Las analogías estilísticas que han sido observadas entre las culturas de Chupícuaro y del centro de México, y la idea de un papel influente de Chupícuaro, se han impuesto, desde hace más de cincuenta años, como el paradigma que estructura la mayoría de los modelos propuestos para reconstituir los procesos culturales del Preclásico reciente en ambas regiones. Para explicar las semejanzas, estos modelos evocan generalmente movimientos de población, influencias de diversa índole, o/y contactos de tipo comercial. Una revisión metódica de las referencias sobre el tema revela que en varios casos el registro arqueológico no siempre sostenta las perspectivas adoptadas. Después de un breve recuento de la historia arqueológica de Chupícuaro, restituiremos las condiciones en las cuales se han construido y modificado las principales interpretaciones. Esta aproximación permite matizar el discurso dominante que se articula en torno al concepto de influencia, y resalta toda la complejidad y la amplitud de las escalas de contactos y de interacciones. [Palabras claves: Mesoamérica, Preclásico, Chupícuaro, Altiplano Central, movimientos de población, contactos comerciales, influencias.]
\end{abstract}

Les relations entre Chupicuaro et le centre du Mexique au cours du Préclassique récent. Une critique des interprétations archéologiques. Les analogies stylistiques observées entre les cultures de Chupicuaro et du centre du Mexique, et le rôle moteur qu'aurait joué Chupicuaro, se sont imposés, depuis plus de cinquante ans, comme le paradigme qui structure la plupart des modèles proposés pour reconstituer les processus culturels dans ces régions au cours du Préclassique récent. Pour expliquer de telles similitudes, ces modèles mettent généralement en scène des mouvements de population, des influences de natures diverses, et/ou des contacts commerciaux. Une révision méthodique des références sur cette problématique dévoile cependant que, dans plusieurs cas, le registre archéologique n'est pas toujours à même de soutenir les perspectives proposées. Après un bref rappel de l'histoire archéologique de Chupicuaro, on s'attachera à restituer les conditions dans lesquelles se sont construites et ont évolué les principales interprétations. Cette approche permet de nuancer le discours dominant qui s'articule autour de l'idée d'influence, et de mettre en lumière la complexité et l'ampleur des échelles de contacts et d'interactions. [Mots clés : Mésoamérique, Préclassique,

* Archéologue, CNRS, UMR 8096, Maison René-Ginouvès (Archéologie et ethnologie), 21 allée de l'Université, 92023 Nanterre cedex [veronique.darras@mae.u-paris10.fr].

Journal de la Société des Américanistes, 2006, 92-1 et 2, pp. 69-110. O Société des Américanistes. 
Chupicuaro, Haut Plateau central, mouvements de population, contacts commerciaux, influences.]

The relationships between Chupicuaro and the Central Highlands of Mexico during Late Formative Period. A reappraisal of the archaeological interpretations. Since more than fifty years, the stylistic analogies observed between the Chupicuaro and Central Highlands cultures, and the supposed influent role of Chupicuaro, appeared as the paradigm which has structured most of the models which reconstitute the Late Formative cultural processes in both regions. To explain the similarities, these models generally refer to population movements, influences of varied nature, and/or comercial relationships. A methodic reappraisal of the scientific background reveals that in several cases, the nature of the archaeological record is not able to support rigorously the proposed perspectives. After revisiting briefly the archaeological history of Chupicuaro, this article will reconstruct the conditions under which the diverses interpretations have been elaborated and how they evolutionated. This reappraisal permits to moderate the dominant position which is articulated around the idea of influence, and reveals all the complexity and width scales of relationships and interactions. [Key words: Mesoamerica, Formative period, Chupicuaro, Central Highlands, population movements, commercial contacts, influences.]

\section{El sorpresivo destino de Chupícuaro}

Desde las excavaciones arqueológicas de los años 1940, la historia del complejo cultural de la región de Chupícuaro (Estado de Guanajuato, ver Figura 1) ha experimentado un destino agitado, caracterizado por cambios de orientación en las interpretaciones y ajustes de diversa índole. Tales evoluciones se refieren básicamente al problema de sus orígenes (Braniff 1965, 1972, 1996, 1998,2000; Florance 1985, 1989, 1993, 2000), a su ubicación temporal (Porter 1956, 1969; Florance 1989, 2000) y, en términos generales, al papel atribuido a las poblaciones que vivían en esta región a finales del periodo preclásico. Desde hace años es un hecho admitido que el conjunto cultural bautizado como " Chupícuaro ${ }^{1}$ marcó la pauta de los principales desarrollos del periodo clásico, no sólo en el Bajío, el centro-norte y el norte de Michoacán, sino también en las regiones noroccidentales (Porter 1956, 1969; Braniff 1996, 2000) y, a partir de este lugar, en el suroeste de Estados Unidos (Haury 1945, 1976; Braniff 1975; Carot 2001). Para el intervalo de su secuencia arqueológica propiamente dicha (que ubicamos ahora entre 600 a.C. y 250 d.C.), este complejo cultural también asume papeles diversos, y en ocasiones contradictorios. Estos últimos se fueron definiendo poco a poco, tras el establecimiento de analogías estilísticas entre ciertos vestigios cerámicos recolectados en algunos sitios de las tierras altas centrales, y los que proceden de Chupícuaro (Vaillant 1931, 1934; McBride 1969, 1974, 1977; Heizer y Bennyhoff 1972; Sanders 1979; West 1965, Bennyhoff 1966; Porter 1956, 1969; Florance 1985, 1989). El discurso dominante presta a Chupícuaro 
una posición influyente respecto a ciertos grupos de la cuenca de México y de los actuales Estados de Hidalgo, Morelos, Puebla y Tlaxcala. Los mismos puntos de vista también defienden la intrusión, en estas últimas regiones, de grupos foráneos afiliados a la tradición « Chupícuaro », la cual habría repercutido en los procesos culturales de la cuenca de México (Vaillant 1931; West 1965; Bennyhoff 1966; Heizer y Bennyhoff 1972; García Cook 1974; García Cook y Rodríguez 1975 etc.). Sin embargo, a este eco ampliamente predominante, aunque no siempre perfectamente demostrado, responden desde hace algunos años posiciones diferentes, que dan cuenta de una realidad más compleja (Florance 1993). Más allá de estos distintos enfoques, también se plantea la hipótesis de contactos económicos: en tal óptica, Chupícuaro suele considerarse como un centro de producción cerámica que habría difundido a larga distancia algunas de sus vasijas y figurillas.

No obstante, una revisión metódica de las numerosas referencias a estas cuestiones revela puntos oscuros así como las incertidumbres que persisten en torno al fenómeno "Chupícuaro » y, en particular, acerca de la naturaleza y la importancia de los nexos que este conjunto cultural habría mantenido con sus vecinos. Tales incertidumbres obedecen, probablemente, a múltiples razones, la primera de las cuales radica en el carácter incompleto de nuestro conocimiento arqueológico de las sociedades preclásicas que vivían en este valle medio del Lerma, no obstante que éste se considere como el foco de la tradición Chupícuaro. Si bien estas lagunas afectan principalmente la comprensión de los orígenes y las modalidades del poblamiento de la región, también impiden un dominio más satisfactorio del marco cronológico y una delimitación territorial pertinente. Por otra parte, las inferencias establecidas a partir de otros contextos también pueden adolecer de las mismas lagunas, debido a los problemas cronológicos que pueden persistir y a enfoques comparativos y metodológicos a veces discutibles. Todos estos parámetros constituyen otros tantos obstáculos que impiden abordar de manera sistemática la delicada cuestión de los nexos entre Chupícuaro y sus vecinos.

Nos proponemos aquí contribuir a la reflexión en torno a estas cuestiones, restituyendo las condiciones en las que se ha construido y en las que ha evolucionado el discurso arqueológico sobre Chupícuaro a lo largo de los últimos cincuenta años. Esta retrospectiva se centrará principalmente en dos aspectos: el problema de los orígenes, y las relaciones que las poblaciones de cultura Chupícuaro establecieron con sus vecinos del centro de México, durante el período Preclásico reciente. Sin embargo, antes de revisar el tenor y el alcance de los discursos tradicionales, es indispensable replantear el marco de la historia de la arqueología en Chupícuaro. 


\section{Recuento del conocimiento arqueológico en Chupícuaro}

El desarrollo de la arqueología del periodo formativo en la cuenca de México, durante el segundo cuarto del siglo veinte (Vaillant 1930, 1931, 1934, 1938; Cummings 1933; Covarrubias 1943, 1950, 1957; Piña Chan 1956; Noguera 1943), y luego en los años 1960, condujo a la definición de un marco cronológico y cultural cuyos principales lineamentos siguen constituyendo, hasta la fecha, los fundamentos de toda investigación arqueológica en las tierras altas del centro (Bennyhoff 1966; Heizer y Bennyhoff 1958, 1972; Fletcher 1963; McBride 1974; Sanders, Parsons y Santley 1979; Tolstoy et al. 1977; Tolstoy y Paradis 1970; West 1965, Niederberger 1976, 1986 etc.). A parte de la preocupación por ordenar los distintos eventos en el tiempo, el descubrimiento de vestigios de estilo olmeca, a la vez en la región del Golfo y en la cuenca de México, permitió en aquel entonces focalizar la atención de los investigadores en un problema crucial: el de las influencias y/o interacciones culturales y, en particular, el de los nexos que pudieron haber existido entre las poblaciones de la cuenca de México y de otras regiones.

En 1945 se puso en marcha un importante programa de rescate en una región situada al occidente de la cuenca de México, más precisamente en el valle medio del Lerma, a proximidad de la ciudad de Acámbaro (Estado de Guanajuato). Este programa, de gran envergadura, estuvo a cargo de Rubín de la Borbolla auxiliado por un grupo de jóvenes arqueólogos, entre los cuales figuraban Román Piña Chan, Elma Estrada Balmori y Muriel Porter Noé. Los objetivos de estos trabajos, motivados ante todo por la urgencia de salvaguardar un patrimonio arqueológico amenazado a corto plazo por la construcción de una presa y la inundación del valle, se inscribieron no obstante en un clima impregnado por las preocupaciones científicas de la época y por los recientes hallazgos de la cuenca de México. De esta manera, el significado de las similitudes estilísticas entre el conjunto cultural bautizado "Chupícuaro », y los vestigios materiales que recientemente se habían descubierto en la cuenca de México, se planteó desde el principio.

Entre 1945 y 1947, las excavaciones realizadas en cinco localidades a proximidad del pueblo epónimo de Chupícuaro, permitieron poner al descubierto varios contextos funerarios, de los cuales procede, hasta la fecha, la mayor parte de nuestros conocimientos. Si bien dichos trabajos resultaron de un compromiso colectivo, correspondió a Muriel Porter $(1956,1969)$ la suerte y la responsabilidad de poder explotar la mayor parte de estos datos arqueológicos, de proponer un marco cronológico y, posteriormente, de establecer inferencias socioculturales. A pesar de algunos errores de apreciación, debidos probablemente a problemas estratigráficos que no comprendió o que eran simplemente insolubles ${ }^{2}$, el estudio minucioso de Porter (1969), basado en comparaciones con las colecciones 


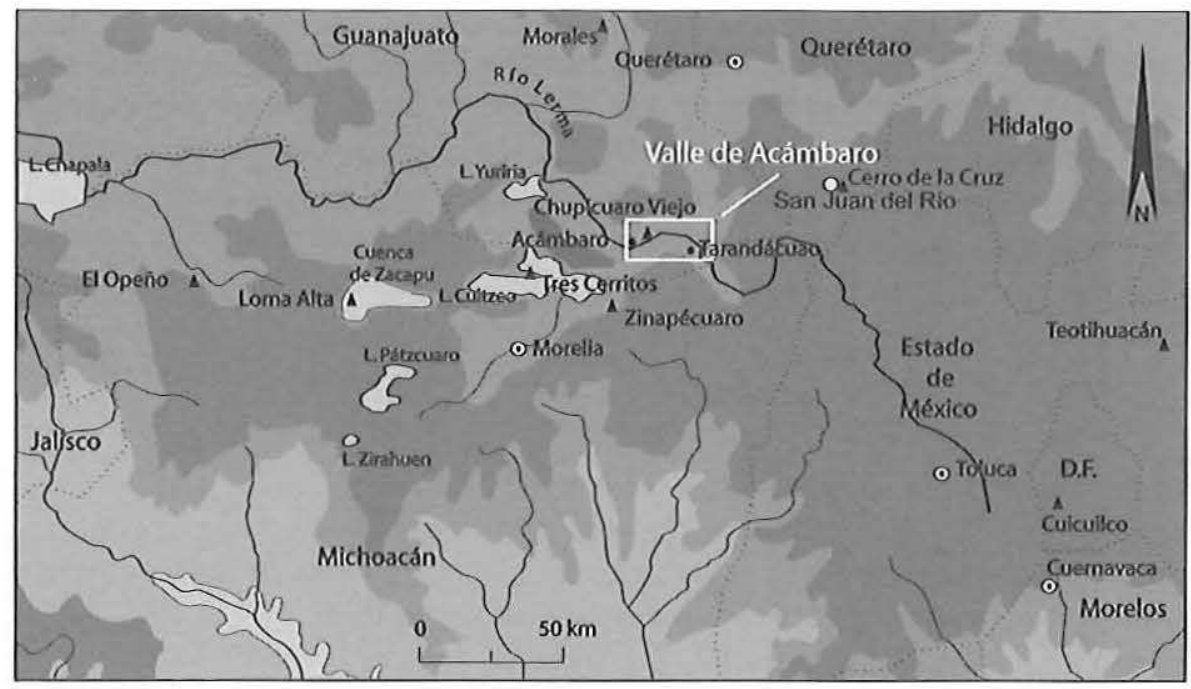

FIG. 1 - El centro-norte de México.

de la cuenca de México, permitió finalmente crear dos fases principales de ocupación y ubicarlas entre 500 y 200 a.C.

Los datos arqueológicos recabados durante estas excavaciones, de excepcional riqueza, conforman el principal corpus de referencia sobre Chupícuaro. Después de 1947 y tras la inundación de una parte del valle, la cultura Chupícuaro permaneció asociada a los límites de los pocos sitios explorados, aun si los muy numerosos hallazgos ilegales realizados en el resto del valle revelaban su dimensión regional. La segunda mitad del siglo xx se caracterizó entonces por cierto desinterés en la región, pese a algunas intervenciones aisladas, aunque muy productivas, en esta área.

No obstante su problemática, centrada en la frontera méxica-tarasca, el proyecto que Shirley Gorenstein (1985) emprendió en 1971 cerca de Acámbaro (Figura 1), tuvo en particular el mérito de arrojar las primeras dataciones de radiocarbono. A Michael Snarkis (1985), quien se dedicó al estudio del material cerámico, debemos la creación de una tercera fase, denominada Mixtlan. Esta fase abarcaría el final del periodo formativo y los muy tempranos inicios del Clásico. En el marco de este proyecto, una campaña de reconocimiento, llevada a cabo por Helen Perlstein Pollard (1985) a proximidad de Acámbaro, permitió asimismo localizar otros asentamiento preclásicos. A mediados de los años 1970, los trabajos de Charles Florance (1989, 1993, 2000), quien había participado en el proyecto de Shirley Gorenstein, constituyen el primer enfoque regional sistemático sobre Chupícuaro. Sus prospecciones en el sector oriental del valle de la presa 
Solís, cerca del pueblo de Puruagüita, lo condujeron a identificar 45 sitios preclásicos y a proponer una reconstitución de los patrones de ocupación del espacio, entre 600 a.C y 100 d.C. Por otra parte, una revisión metódica del material cerámico publicado por Porter, aunada a una meticulosa comparación con su propia muestra de superficie, aportó precisiones fundamentales al marco cronológico. Finalmente, corresponde a Florance el mérito de haber iniciado una reflexión pertinente y de fondo sobre los orígenes del poblamiento del valle, y de haberse esforzado por ubicar a las poblaciones Chupícuaro dentro del espacio mesoamericano, en particular con respecto a los desarrollos contemporáneos de la cuenca de México. Posteriormente, en 1984, los sondeos realizados por Carlos Castañeda y Yolanda Cano en el sitio de La Virgen no arrojaron resultados de orden cronológico, debido a las importantes perturbaciones ligadas a los saqueos. Pero este aportó una información importante: la existencia, en este sitio, de un patrón arquitectónico complejo, en forma probable de patio hundido (Castañeda y Cano Romero 1993). Finalmente, en los años 1980 y 1990, ciertos reconocimientos aislados a cargo del INAH permitieron incrementar el número de ocupaciones arqueológicas alrededor del vaso de la presa.

Fue preciso esperar hasta el año de 1998 para que se pusiera en marcha una nueva campaña de reconocimiento in situ, con el objeto de apreciar las condiciones reales de campo y evaluar objetivamente el potencial arqueológico del valle. Este trabajo realizado por el CEMCA ${ }^{3}$, permitió poner en evidencia la magnitud de los procesos de destrucción de los contextos antiguos, debido a la presencia de la presa, al papel devastador de los saqueos y al desarrollo de los cultivos intensivos. Pese a esta coyuntura poco favorable, se formuló un programa con una fuerte orientación geoarqueológica; desde entonces se han llevado a cabo seis temporadas de prospección y/o de excavación, en los sectores de Puruagüita y San José Hidalgo (Darras et al. 1999; Faugère, Darras y Durlet 2000; Darras y Faugère 2001, 2002, 2003, 2004, 2005a, s.d.a, b et c).

Tal es, en resumidas cuentas, la historia de los trabajos arqueológicos realizados en la región de Acámbaro, donde se describió por primera vez el conjunto cultural llamado Chupícuaro. Sin embargo, queda claro que los límites del valle jamás constituyeron una frontera geocultural pertinente. En los años 1970 y 1980, campañas de prospección de superficie, realizadas por el Salvamento Arqueológico del INAH en el marco del programa Gasoducto, o coordinadas por Enrique Nalda, en el marco del proyecto Lerma Medio, aportaron una serie de precisiones acerca de la extensión del complejo cultural más allá de los límites de su lugar de descubrimiento. En el transcurso de estas exploraciones se cartografiaron numerosos sitios preclásicos en las regiones de La Gavia, Salvatierra y Salamanca-Yuriría, alrededor del lago de Cuitzeo, así como en la región de Zinapécuaro (Sánchez Correa y Zepeda 1981, 1982a y b; Contreras Ramírez y Durán Anda 1982; Nalda 1978, 1979, 1981). De la misma manera, el proyecto Atlas Arqueológico de Guanajuato permitió el registro de varios sitios preclási- 
cos (Crespo y Castañeda 1979). Sin embargo, las descripciones de ciertas de las colecciones cerámicas obtenidas en los sitios del Estado de Guanajuato, no permiten determinar si realmente se trataba de sitios afiliados al mismo conjunto cultural que el del valle de Acámbaro, o si se trataba de complejos distintos, pero que en sus principales lineamentos compartían la misma tradición alfarera. En cambio, las similitudes entre Cuitzeo, Ucareo y la región de Chupícuaro, que otros autores (Porter 1956) habían subrayado anteriormente, se confirmaron y contribuyeron a delimitar a grandes rasgos un espacio geográfico ocupado por poblaciones con una misma filiación cultural y que, muy probablemente, conformaban una unidad político-territorial durante el Preclásico reciente (veáse el trabajo de Crespo 1991). Además de estos reconocimientos de superficie, otros proyectos, con excavaciones o sondeos estratigráficos, han mejorado el conocimiento del complejo Chupícuaro. Los trabajos en el sitio del Barrio y Cerro de la Cruz (Estado de Querétaro), así como en Santa María del Refugio (Estado de Guanajuato), refuerzan las hipótesis de una extensión del territorio «Chupícuaro » hacia el actual Estado de Querétaro y el centro de Guanajuato (Crespo 1991, 1992; Castañeda, Crespo y Flores 1996; Saint Charles 1996, 1998; Saint Charles y Argüelles Gamboa 1991). El proyecto dirigido por Dan Healan en la región de Ucareo sobre la problemática de la obsidiana, permitió asimismo evidenciar una ocupación preclásica (en Araro y Bartolilla, Estado de Michoacán), cuyas características materiales se inscriben directamente dentro de la tradición cultural definida en el valle de Acámbaro (Healan y Hernández 1999; Hernández 2001).

Estos distintos hallazgos corresponderían pues a manifestaciones arqueológicas del Preclásico reciente. Sin embargo, la historia de Chupícuaro no parece limitarse a estos sitios. Otros asentamientos, un poco más lejanos, que datan por lo general del final del Preclásico y de principios del Clásico, también proporcionaron complejos cerámicos aparentemente ligados a Chupícuaro. Tal es el caso del sitio de Morales (Guanajuato), estudiado en 1965 por Beatriz Braniff(1998), y de Loma Alta en Michoacán (Arnauld, Fauvet-Berthelot y Carot 1993; Carot 1992, 1993, 2001). Para el sitio de Morales, nos referimos a los materiales de la fase Morales, fechada entre 300 y 100 a.C., aunque el parentesco estilístico sólo se logra establecer para la fase Mixtlan, la más tardía de Chupícuaro ${ }^{4}$ e identificada en todo el valle de Acámbaro (Snarkis 1985; Florance 1989; Darras y Faugère s.d.c). Según Carot (2001, p. 64), el complejo Loma Alta, esencialmente durante sus dos primeras etapas (Loma Alta I y IIa, 100 a.C. - 250 d.C.), aparece como un heredero de la tradición Chupícuaro. Asimismo, la expansión hacia el norte se desprendería de ciertos hallazgos cerámicos en los Estados de Jalisco (Cerro Encantado) y de Zacatecas (Juchipila, Tunal Grande), que recuerdan el material de la fase Morales (Bell 1974; Jiménez 1995).

En conclusión, si bien esta reseña apunta hacia la falta de programas arqueológicos de envergadura en el valle considerado como el foco de la cultura 
Chupícuaro, también resalta los aportes de trabajos realizados en otras regiones, los cuales plantean el problema crucial de la extensión geográfica de la « cultura » y de la « tradición » Chupícuaro a lo largo del Preclásico reciente y del Clásico.

En lo concerniente a los datos arqueológicos de las regiones del centro de México relacionados con nuestra problemática, disponemos de varias referencias, las cuales fueron objeto de una excelente síntesis por parte de Harold McBride (1969). Este autor establece un inventario de las localidades que proporcionaron vestigios relacionados con Chupícuaro, independientemente de su ubicación temporal. Con posterioridad a esta fecha, otros hallazgos han venido a enriquecer dicha lista, no sólo en la cuenca de México, sino también en la zona Tlaxcala-Puebla (García Cook 1974; García Cook y Rodríguez 1975; Trejo 1975; Guevara Ruiseñor 1975) ${ }^{5}$. Finalmente, varios trabajos más recientes en estas mismas regiones continúan ampliando el inventario. En la actualidad, únicamente para las regiones del altiplano central (cuenca de México y regiones adyacentes), nuestras investigaciones bibliográficas han localizado 29 sitios o sectores del Preclásico reciente, que estarían relacionados con la tradición Chupícuaro ${ }^{6}$. La lista de estos sitios, que seguramente no es exhaustiva ${ }^{7}$, aparece en el cuadro anexo y en la Figura 2.

\section{LA EVOLUCIÓN Y LA INCERTIDUMBRE DE LOS DISCURSOS}

Como acabamos de ver, los descubrimientos arqueológicos de 1946 en el valle de Acámbaro se interpretaron con base a supuestas relaciones interregionales las que no pueden ser admitidas sin discutir. En efecto, desde el establecimiento de las analogías estilísticas y la elección de un punto de vista articulado en torno al concepto de « influencia », se ha concedido poco espacio a la reflexión crítica y razonada ${ }^{8}$. Sin embargo, no se puede menos que reconocer que la gran diversidad de contextos, aunada al número de referencias y comparaciones obligadas con una tradición cerámica de la cual Chupícuaro constituiría la pieza clave, terminó creando una amalgama compleja. Esta amalgama, que puede abarcar escalas temporales y espaciales muy amplias y reunir indiscriminadamente vestigios de distinta índole, ha venido generando confusiones e inferencias a veces abusivas. El carácter aproximado de ciertos discursos en torno a la idea de movimientos de poblaciones, a las nociones de influencia, de semejanzas estilísticas, de comercio, e incluso de interacciones ideológicas, nos recuerda hasta qué punto el registro arqueológico se encuentra a veces incapacitado para proveer herramientas de medida pertinentes de estos distintos conceptos. Por otra parte, como muy tempranamente lo señalara Florance (1989, p. 625; 2000, p. 24), han surgido posiciones opuestas, según fueran concebidas éstas desde la región del Bajío o, al contrario, desde las regiones del centro (cuenca de México, Tlaxcala, etc.). Finalmente, cabe señalar que los cambios que se propusieron en las inter- 

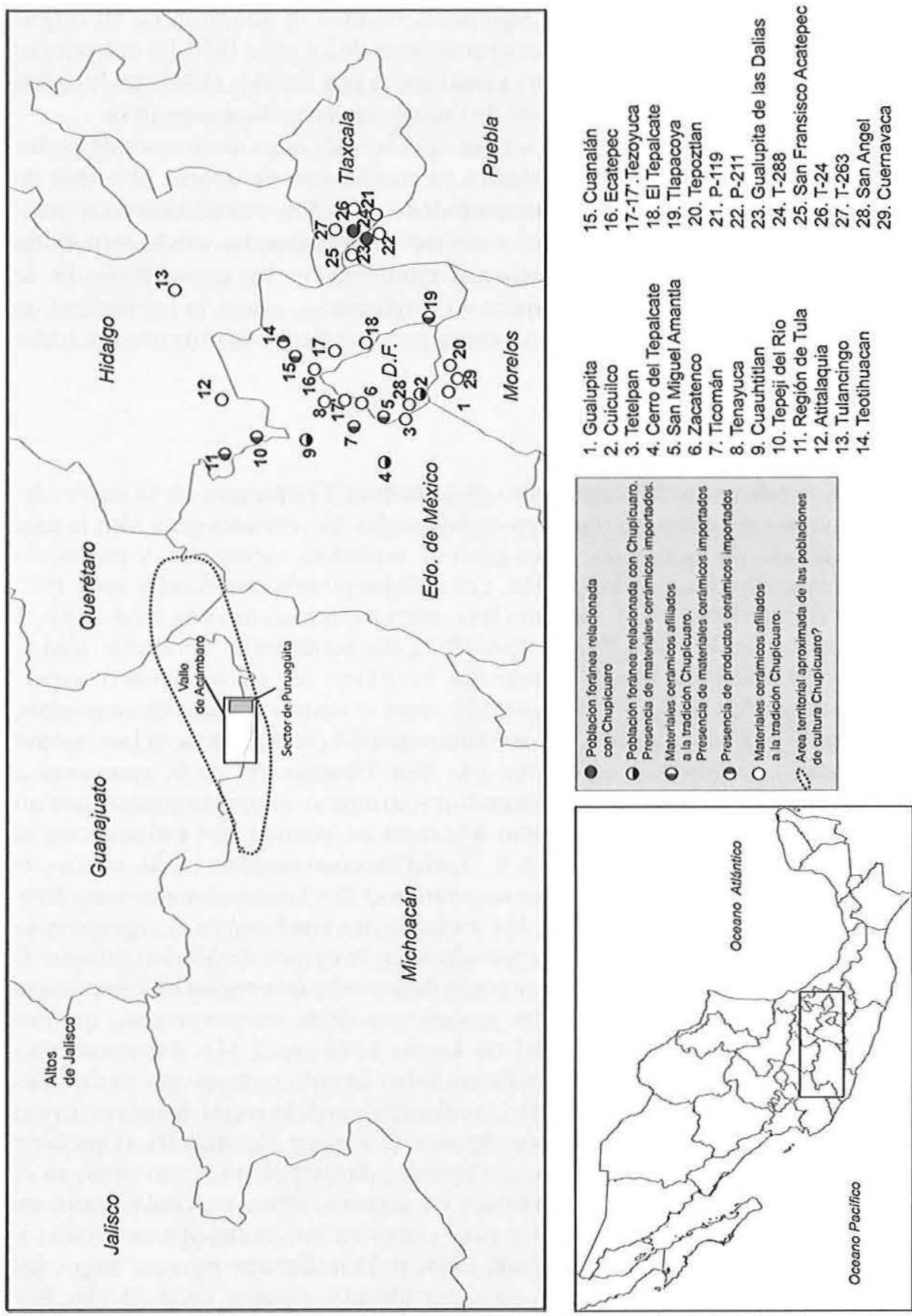

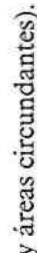
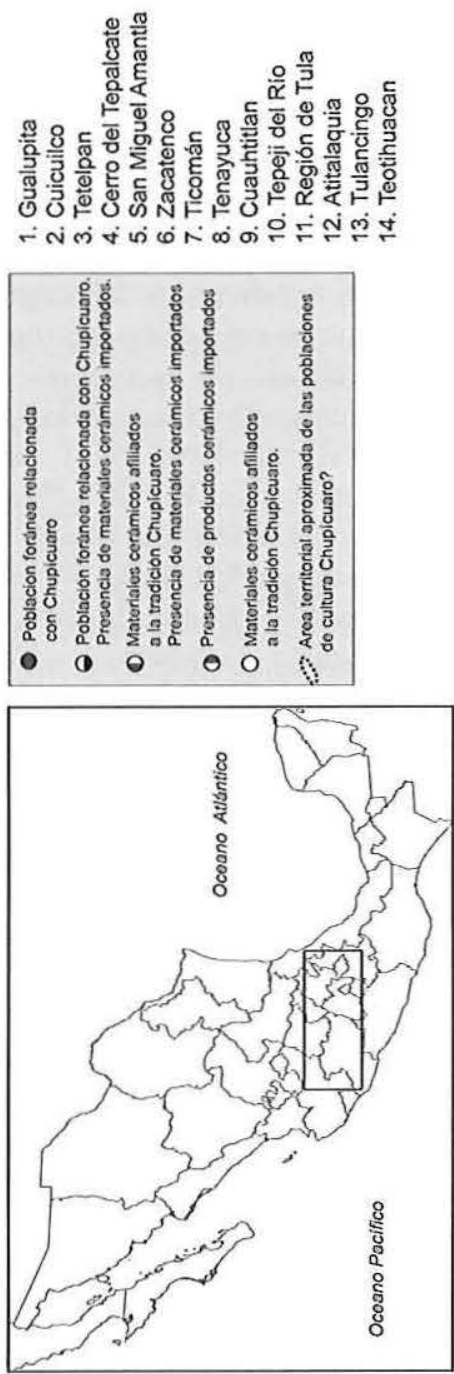
pretaciones relativas al valle de Acámbaro, siempre se apoyaron en un corpus arqueológico inmutable, a saber las excavaciones de los años 1940, las colecciones cerámicas procedentes de sondeos y analizadas por Snarkis (1985) en los años 1970, o las colecciones de superficie de Puruagüita constituidas en 1975.

Como quiera que sea, parece ser que la validez de estos discursos sólo podrá ratificarse o matizarse cuando estemos en condiciones de oponer al corpus de referencia, datos arqueológicos actualizados y variados, procedentes de contextos estratigráficos perfectamente controlados. Actualmente existe demasiada incertidumbre en torno a los aspectos cronológicos, las modalidades de la supuesta expansión de los materiales «Chupícuaro », o aun la legitimidad de ciertas correspondencias estilísticas, como para justificar y fijar de una vez todas las posiciones actuales.

\section{Orígenes fluctuantes}

Las condiciones del surgimiento de la cultura Chupícuaro en la región del valle medio del Lerma, permanecen desconocidas. En términos generales, la tesis de un desarrollo autóctono nunca gozó de verdadera aceptación, y prevaleció más bien la idea de una colonización. Los trabajos pioneros, realizados entre 1945 y 1947 (Porter 1956, 1969), así como las posteriores temporadas de sondeo que se llevaron a cabo en 1973 (Gorenstein 1985), no permitieron evidenciar alguna ocupación anterior al Preclásico superior. El análisis de las colecciones de superficie, a cargo de Charles Florance (1985), va en el mismo sentido. En su primera publicación, del año de 1956, Muriel Porter guardó cierta reserva: si bien señaló la ausencia de vestigios anteriores a la fase Ticomán (es decir, anteriores a 500 a.C.) en las colecciones que ella examinó, al mismo tiempo puntualizó que no se hallaba en condiciones de probar que estos no existían. Sin embargo, en su segunda publicación (Porter 1969, p. 7), ella evocó el carácter tardío del desarrollo Chupícuaro ("The Preclassic occupation of this Lerma river area must have taken place as early as 300 B.C. but probably not much before »); agregó que, debido a la fuerte ocupación que prevalecía en la cuenca de México durante el Preclásico temprano y medio, no se podía descartar que la región de Chupícuaro hubiese sido poblada por grupos procedentes de la cuenca misma, quienes habrían progresado a lo largo del río Lerma (ibid., pp. 8-11). Asimismo, esta autora opina que esos grupos pudieron haber llevado consigo sus tradiciones cerámicas y sus cultos. Según Porter, la colonización de la región habría ocurrido entre 400 a.C. y 300 a.C., lo cual correspondería a la fase Ticomán III o Cuicuilco III para la cuenca de México (según Heizer y Bennyhoff 1972), es decir, en el momento preciso en que se observan en algunos sitios, particularmente en la región de Cuauhtitlan, cambios muy claros en las tradiciones cerámicas y analogías con Chupícuaro (McBride 1974, p. 256). En una primera etapa, las hipótesis de Porter fueron retomadas por algunos autores, en particular por 
Beatriz Braniff (1965, p. 15), quien consideró que la ausencia de vestigios más antiguos en el Estado de Guanajuato sugería una entrada tardía desde las regiones del centro. Posteriormente, esta misma autora (Braniff 1972, p. 40) propuso que el poblamiento de las regiones en las cuales se manifiestan vestigios cerámicos relacionados con la tradición de Chupícuaro, habría ocurrido más bien en el transcurso del Preclásico medio y sería un derivado de la cultura Tlatilco. Finalmente procedió a una revisión completa de su posición inicial al observar las correspondencias estilísticas entre El Opeño, Capacha y Chupícuaro (pero también Tlatilco). En esta última versión, los inicios de la tradición cultural Chupícuaro datarían, según ella, de 800 a.C. aproximadamente, y Chupícuaro sería " un heredero directo de aquel complejo de Occidente » (Braniff 1996, p. 60; 1998, p. 77).

En su tesis doctoral, en los años 1980, Charles Florance (1989, pp. 623-626; 2000 , p. 24) analizó las distintas hipótesis existentes en torno a los orígenes del poblamiento de la región de Chupícuaro, y señaló las contradicciones que éstas contenían. A este investigador debemos un tratamiento metódico del problema, a partir de comparaciones sistemáticas entre sus colecciones de superficie, el corpus de Porter, los materiales recolectados en la cuenca de México y los materiales procedentes del Occidente, en particular del Estado de Jalisco. Este enfoque estuvo motivado, en parte, por el afán de corroborar o invalidar los discursos en boga en la cuenca de México (Florance 1989, p. 683), fomentados entre otros por Bennyhoff. Desafortunadamente, los distintos cambios ocurridos, entre 1985 y 2000 , en su visión del problema se dieron a partir del mismo corpus arqueológico. En un primer momento, Florance (1985, p. 45) adoptó las primeras sugerencias de Porter y estimó que Chupícuaro debía considerarse como parte de un sistema estatal en plena expansión, cuyo corazón se habría situado en Cuicuilco y que habría tenido una dimensión militar. Sin embargo, las posiciones que este mismo autor (Florance 1989, pp. 663,682) adoptó en su tesis ya estaban más matizadas: de hecho, tomaba en cuenta otros modelos, en particular el de un posible desarrollo autóctono o de una expansión desde el Occidente, especialmente desde Jalisco, en el transcurso del Preclásico medio (durante la fase San Felipe, ibid., p. 673). Fue en sus publicaciones posteriores cuando Florance (1993; 2000) propuso un punto de vista más categórico. Su reflexión se articuló entonces a partir de una revisión del inagotable corpus de Porter y de nuevas comparaciones. Con base en este trabajo, estima que, durante la fase Chupícuaro temprano, se habría producido un poblamiento del valle a partir del Occidente (Florance 2000, p. 29).

Las fluctuaciones que se observan en estos distintos discursos, traducen por supuesto las incertidumbres de sus autores e ilustran los límites del corpus arqueológico sobre el cual se fundamentan. Cabe observar en particular que la propuesta de Porter, en 1956, y luego en 1969, a saber, una colonización a lo largo del Lerma desde la cuenca de México, durante la fase Ticomán III, se contrapone 
a una corriente que le es, no obstante, contemporánea y que fue iniciada por Vaillant, y luego sostenida por Bennyhoff, Heizer, McBride o Sanders.

En efecto, del lado de la cuenca de México los puntos de vista fueron elaborándose desde perspectivas distintas. La adopción de una postura única que otorga a Chupícuaro un papel predominante sobre ciertos sitios, e incluso una posible intrusión física en la cuenca, parece descartar de entrada la hipótesis inicial de Porter de alguna colonización del Bajío procedente de esta región, por lo menos durante el Preclásico reciente. Sin embargo, contrariamente a lo que señala Florance (2000, p. 24), ni Bennyhoff, y ni siquiera McBride, declararon que concebían Chupícuaro como el fruto de un proceso autóctono. En efecto, sus hipótesis acerca de una posible intrusión en la cuenca desde el Bajío, no revelan en absoluto sus opiniones acerca de las modalidades del desarrollo cultural de Chupícuaro. En realidad, es preciso reconocer que la posición de los investigadores que trabajan en la cuenca de México, no los ha conducido realmente a interrogarse acerca del poblamiento y el desarrollo de una región que supuestamente fue el origen de tantos y tan drásticos cambios en su área de estudio.

\section{¿Una intrusión chupicuareña en la cuenca de México y sus alrededores?}

A partir de la década de 1930, se evocaron reiteradamente vínculos entre la región de Chupícuaro y la cuenca de México y se adopta rápidamente la hipótesis de unos flujos migratorios. Los primeros paralelos estilísticos y las primeras hipótesis emanaron de Georges Vaillant (1930, pp. 136-137; 1931, pp. 332, 362363): al dar a conocer el resultado de sus excavaciones en Ticomán, este autor comparó cuatro figurillas recogidas en su sitio y clasificadas como $\mathrm{H} 4$ de acuerdo con su tipología, y otras presentes en abundancia en la región de Chupícuaro (Figuras 3 y 4). Cabe recordar sin embargo que a finales de los años 1920 la cerámica recolectada en esta última región seguía considerándose como perteneciente a la cultura tarasca, motivo por el cual el establecimiento de correlaciones continuaba siendo difícil (Mena y Aguirre 1927). Por consiguiente, Vaillant relacionó, de manera prudente y más amplia, las figurillas $\mathrm{H} 4$ y sus derivados con complejos culturales que se habrían desarrollado en los Estados de Morelos (Figura 4), Querétaro o Guanajuato. Al proceder de esta manera, sobreentendía el carácter exógeno de estas figurillas en la cuenca de México, aunque sin brindar mayores precisiones. Finalmente, los cambios drásticos observados, a nivel más global, en las tradiciones cerámicas de las fases Cuicuilco III y Ticomán III, lo condujeron a sugerir la existencia de eventuales afinidades étnicas entre Ticoman y Cuicuilco. Según Vaillant (1935, pp. 62-64), ciertos grupos procedentes del norte o del noroeste habrían colonizado una parte de la cuenca de México, especialmente Cuicuilco, y habrían llevado consigo tradiciones cerámicas perfectamente establecidas. Desde 1935, aunque sin mencionar posibles migraciones, 


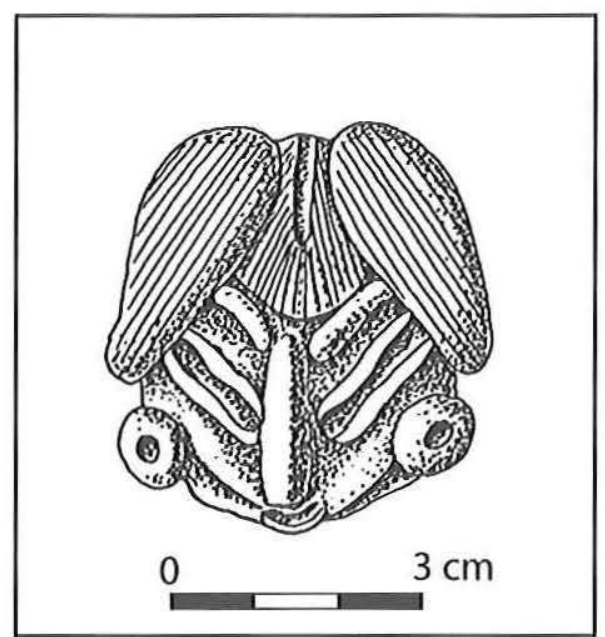

FIG. 3 - Figurilla de tipo $\mathrm{H} 4$ procedentes de las excavaciones del sitio JR 24 - La Tronera (proyecto Chupícuaro CEMCA).

Noguera evocó específicamente a Chupícuaro como probable origen de las manifestaciones culturales de la fase Teotihuacan I.

Como es sabido, las ideas pioneras de Vaillant fueron retomadas y desarrolladas por West (1965), Bennyhoff (1966, p. 20), Heizer y Bennyhoff (1972, p. 99). Por lo que puede deducirse de los escritos de estos autores, las incursiones en la cuenca se habrían producido por lo menos en dos ocasiones, a principios del Preclásico reciente y a finales de este periodo. Según ellos, la penetración de la cuenca desde el norte y el noroeste habría ocurrido primero durante la fase Ticomán I (o Cuicuilco I) ${ }^{9}$, es decir, entre 600 y 500 a.C., sin aportes significativos de población durante los siglos posteriores (Bennyhoff 1966, p. 20); sin embargo, habría ocurrido una renovación de los contactos durante la fase Ticomán IV (o Cuicuilco IV; 200-100 a.C.), la cual se habría manifestado a través de un incremento de los elementos de estilo Chupícuaro (en particular, las figurillas H4, los recipientes con pedestal, etc.; Heizer y Bennyhoff 1972, p. 100; Müller 1990, p. 256). En la opinión de Müller, la aparición de los elementos Chupícuaro remontaría a la fase Cuicuilco III, es decir, entre 400 y 200 a.C. Finalmente, para Heizer y Bennyhoff, el colapso de Cuicuilco y los trastornos que marcan el final del periodo preclásico (fases Tezoyuca y Patlachique), estarían parcialmente relacionados con una presión extrema procedente del norte y del noroeste, es decir; de Chupícuaro (Bennyhoff 1966, p. 21). Más tarde, McBride (1974, p. 256) se adhiere también a esta idea, al plantear que el sitio de San José Cuauhtitlán habría sido colonizado por grupos estrechamente vincula- 


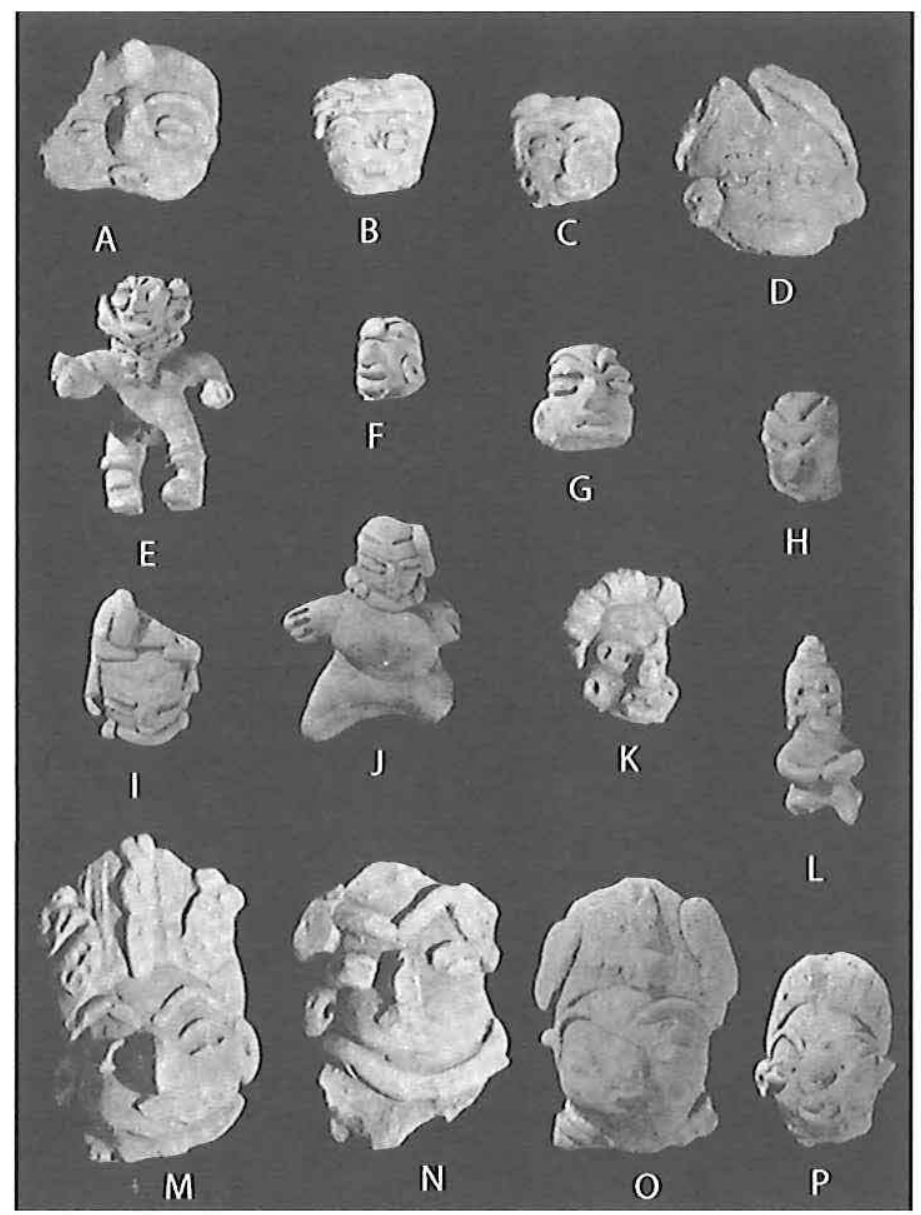

FIG. 4 - Figurillas de tipo H4 procedentes de Gualupita, Morelos (según Vaillant 1934, figura 11, p. 43)

A.C: tipo H4a, comprada en Gualupita

D: tipo H4a-c, tipo de transición, comprada en Gualupita

E-G: tipo H4b, comprada en Ticomán

H: tipo H4b, trinchera D, corte I II, excavaciones en Gualupita

I: tipo $\mathrm{H} 4 \mathrm{c}$, trinchera $\mathrm{A}$, excavaciones en Gualupita

$\mathrm{J}$ t tipo $\mathrm{H} 4 \mathrm{c}$, trinchera C, excavaciones en Gualupita II

K-L: tipo H4c, comprada en Gualupita

M: tipo H4d, trinchera C, corte IV, excavaciones en Gualupita

N-O: tipo H4d, obsequio del Sr. Bourgeois

P: tipo H4d, comprada en Gualupita 
dos con Chupícuaro, durante la fase Cuicuilco III, es decir, a partir de 400 a.C. No obstante, en una publicación posterior McBride (1977, p. 389) precisa que el flujo migratorio habría procedido de la región de Tula, donde se habrían encontrado figurillas H4d ${ }^{10}$. Por su parte, Sanders, Parson y Santley (1979, p. 104), interpretaron inicialmente el material cerámico de los 13 sitios Tezoyuca como la posible expresión de una intrusión étnica que, de acuerdo con las sugerencias de West, podía proceder de Chupícuaro. Posteriormente, la complejidad de los contextos en que aparecía la cerámica de la fase Tezoyuca (fechada tentativamente de 300-100 a.C.), los llevó en considerar que el problema Tezoyuca no podía contentarse de esta única explicación. A su vez, los trabajos de Piña Chan y Pareyón (Pareyón 1961) en el Cerro del Tepalcate les hicieron evocar, entre otras hipótesis, la posibilidad de una presencia chupicuareña en el lugar. Finalmente, las investigaciones realizadas en los años 1970 en la región de Tlaxcala y Puebla, permitieron identificar varias similitudes con la tradición Chupícuaro (Figura 5). Estos nexos, que suelen explicarse en términos de influencia o de interrelaciones, se habrían acentuado también durante la fase Tezoquipan (300100 a.C.; García Cook 1974, p. 13). Sin embargo, en dos casos se plantea la hipótesis de una verdadera presencia en la región de grupos foráneos afiliados a la tradición Chupícuaro, en particular para los sitios de Gualupita de las Dalias y T288 (García Cook y Rodríguez 1975, pp. 6-7).

Como se advierte, estos puntos de vista, elaborados desde el altiplano central se articulan en torno a la idea de una intrusión física de grupos de filiación Chupícuaro, probablemente originarios del valle medio del Lerma: tal intrusión podría haber ocurrido a distintas escalas - desde un flujo migratorio de gran envergadura, hasta desplazamientos de menor importancia - y de acuerdo con distintas modalidades temporales. Aunque Bennyhoff sugiere que a la primera colonización, entre 600 y 500 a.C., no le sucedieron aportes demográficos importantes, si hemos de creer a McBride y García Cook, otras irrupciones habrían ocurrido después de 400 a.C., es decir durante la fase Cuicuilco III. Además, si bien Bennyhoff no lo expresa claramente, la presión extrema procedente del norte y del noroeste, que ocurre durante la fase Cuicuilco IV, es decir, a partir de 200 a.C., también podría vincularse con otro movimiento de población desde esta última región. Como quiera que sea, la hipótesis de un movimiento poblacional desde el Bajío durante la fase Ticomán I, no es incompatible, a priori, con la de Florance y Braniff quienes, como lo vimos más arriba, terminaron atribuyendo a las poblaciones preclásicas del valle medio del Lerma, un origen occidental. Estos distintos planteamientos describirían, por lo tanto, un avance desde el Occidente hasta el Bajío, entre los siglos viII y vi a.C. y, posteriormente, hacia la cuenca de México, a partir del siglo vi a.C. 


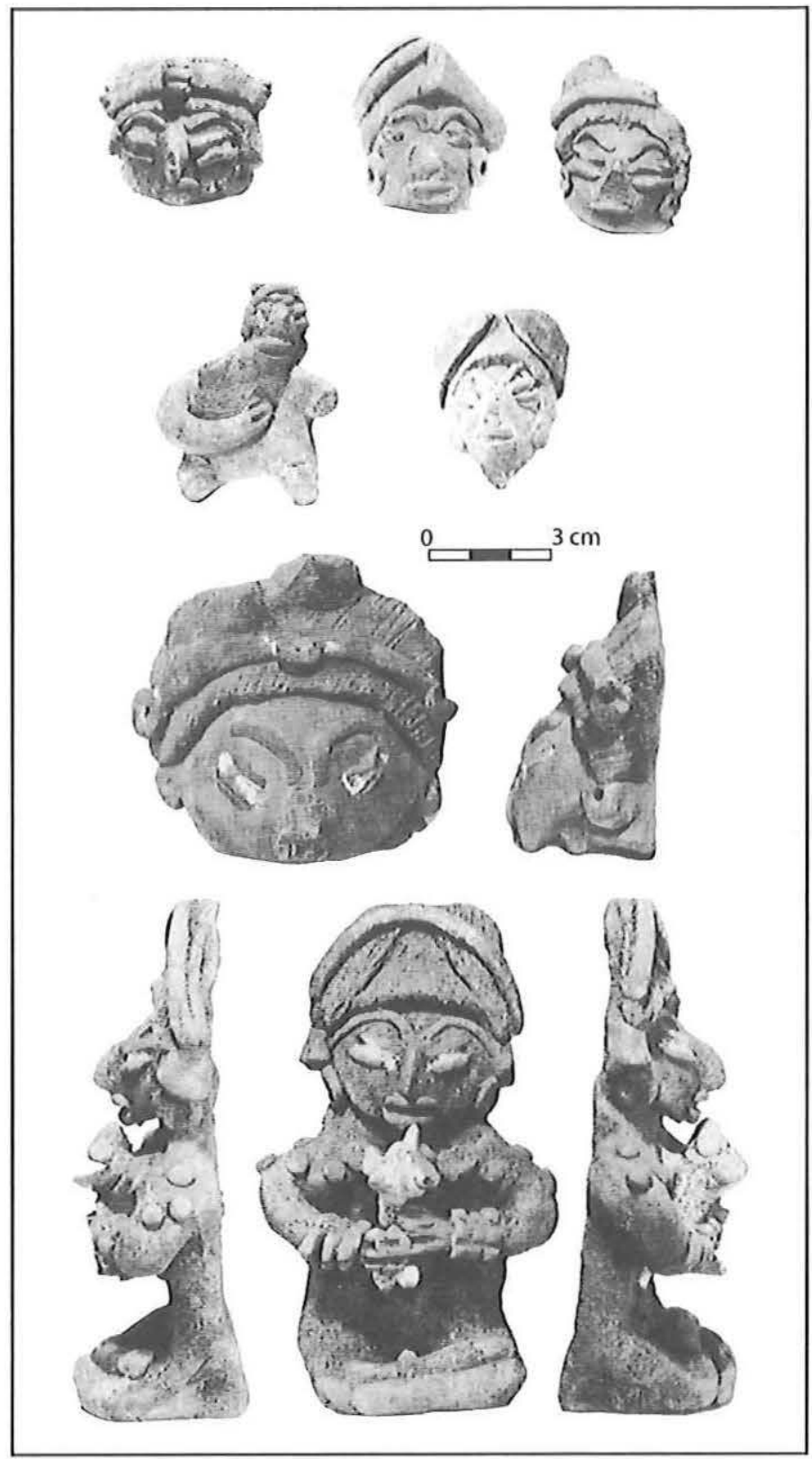

FIG. 5 - Figurillas de tipo $\mathrm{H} 4$ procedentes de las excavaciones de Gualupita de las Dalias (según Garcia Cook y Rodríguez 1975, figuras 27, 28, 29). 


\section{Entre influencias y reciprocidad...}

\section{¿La cuenca de México bajo influencia?}

Al lado de la corriente que favorece la idea de flujos migratorios, existe, aunque de manera menos definida, la hipótesis de una influencia masiva que se habría dado en el ámbito de la alfarería. Ya desde 1969, McBride (1969, pp. 3338) recordaba que se contaba con suficientes evidencias arqueológicas como para postular la existencia de una tradición alfarera Chupícuaro dotada de enorme fuerza, que habría ejercido influencia en gran parte del Centro y Centro-Norte de México, entre 500 a.C. y principios de nuestra era. Una vez que los distintos protagonistas de los años 1960 hubieron marcado la pauta, tal fue, en términos generales, la interpretación que adoptó la mayoría de los investigadores a quienes tocó observar correspondencias entre sus materiales y los materiales característicos de Chupícuaro. En el estado actual de la información, unos 29 sitios aparecen mencionados en la literatura con influencias del Occidente, y en particular de Chupícuaro (Figura 2). Sin embargo, pocas publicaciones aportan las precisiones necesarias acerca de la naturaleza y la intensidad de esta supuesta influencia. Además, ciertos vínculos se establecieron, al parecer, de manera un tanto apresurada, sobre la base de vagas semejanzas que merecerían certificarse. En fin, en numerosos casos la ubicación cronológica de estas manifestaciones no es nada segura. En consecuencia, si abarcamos la totalidad del marco cronológico de referencia y si admitimos que el conjunto cultural llamado "Chupícuaro » efectivamente dio origen a los distintos elementos que componen su tradición cerámica - lo cual, a nuestro parecer, aún falta demostrarse -, uno debe de preguntarse a través de cuáles medios se habría ejercido su influencia. De esta literatura se desprende que el aporte de Chupícuaro se habría ejercido directa o indirectamente, a través de la propagación de su estilo cerámico y/o a través de la difusión de productos manufacturados.

En lo que toca estrictamente a la idea de una propagación del estilo « chupicuaro », el tenor de la información recogida en la literatura nos autoriza a vislumbrar varios escenarios posibles, los cuales, una vez más, se fundamentan únicamente en la cerámica:

- La instalación de grupos chupicuareños en la cuenca de México a principios de la fase Ticomán I, y quizás durante las fases Cuicuilco III y IV, implicaría la idea de que éstos debieron reproducir, y quizás imponer en su nuevo hábitat sus propias tradiciones cerámicas. La fuerza de estas últimas habría afectado profunda y directamente a las demás producciones locales. Tal sería el caso de sitios como Cuicuilco, Ticomán, San José Cuauhtitlán, Gualupita de las Dalias, T 288, y El Cerro del Tepalcate (Vaillant 1931; Bennyhoff 1966; Heizer y Bennyhoff 1972; McBride 1974; García Cook y Rodríguez 1975; Müller 1990). 
- A partir de este esquema evolutivo que supone una intervención directa y permite discernir varios polos en la cuenca de México, podemos emitir la hipótesis de un fenómeno de expansión en forma de mancha de aceite. Ciertas poblaciones que a priori nada tenían que ver con el complejo cultural del valle medio del Lerma, podrían haber recibido una influencia indirecta, quizá a través de sitios tales como Cuicuilco o Ticomán. La influencia de Cuicuilco como centro regional, podría haber alentado esta expansión estilística. La incorporación de elementos exógenos $o$, en ciertos casos, la adopción más general de nuevos conceptos cerámicos, habrían desembocado en la formación de un estilo local propio, sin que este proceso fuera acompañado de contactos directos. Los complejos cerámicos que parecen derivarse de la tradición Chupícuaro bien podrían haberse constituido en el marco de un proceso consciente de imitación, apropiación e identificación o, al contrario, en el marco de una incorporación paulatina mucho más inconsciente.

- También el consumo de productos manufacturados importados directamente de Chupícuaro, y el éxito que se les atribuyó, podría haber generado en los lugares abastecidos imitaciones fieles y reinterpretaciones locales con la formación progresiva de un estilo propio.

Como se ve, estos posibles esquemas evolutivos colocan a la cuenca de México y sus áreas vecinas bajo el signo de una influencia, y evocan más bien un flujo unilateral o mayoritario, de personas, conceptos alfareros y bienes desde Chupícuaro. Sin embargo, otros modelos describen contactos de distinta índole que suponen mayor reciprocidad.

El caso de la región de Puebla-Tlaxcala

Generalmente, los trabajos realizados en la región de Puebla-Tlaxcala durante los años 1970 interpretan la presencia de elementos de estilo Chupicuaro como el resultado de una influencia externa. Si bien los protagonistas piensan que la influencia del Occidente, y en particular de Chupícuaro, habría generado simultáneamente imitaciones fieles y/o reinterpretaciones locales de conceptos cerámicos, también optan por la idea más general de un intercambio (Garcia Cook 1974, p. 11) o de interrelaciones con sus propias repercusiones en el Occidente (Guevara Ruiseñor 1975, p. 138). Así, según estos trabajos, el surgimiento de nuevos elementos, tales como ciertas figurillas y las orejeras sólidas, a partir de la fase Texoloc (800-300 a.C.), aparecería como un indicio de tales contactos con el Occidente (García Cook ibid.). Estos se habrían iniciado durante el Preclásico medio y habrían perdurado hasta el Clásico, y se expresarían a través de un proceso dinámico de transculturación en ciertos ámbitos de la cultura material y de la esfera ideológica. 
La región de Acámbaro, ¿centro versus periferia?

En la parte este del valle de Acámbaro, aparentemente los datos no parecen sostener la preeminencia de Chupícuaro sobre las tierras altas centrales, como la plantean los discursos elaborados desde la cuenca de México. Al contrario, las perspectivas de Florance $(1989 ; 1993 ; 2000)$ describen una situación más compleja basada sobre una reciprocidad desigual, donde interactuan factores múltiples. Como lo indica claramente el título de su último artículo, este autor plantea sus postulados en términos de centro versus periferia (Florance 2000). Sus últimos dos trabajos (Florance 1993; 2000) ${ }^{11}$ reafirman y desarrollan una postura que ya se encontraba esbozada en su tesis, a saber, la hipótesis de una preeminencia de la cuenca de México sobre Chupícuaro en el momento de su apogeo. En efecto, al comparar el grado de desarrollo de estas dos regiones, Florance (1993, p. 25) deduce que la primera se hallaba en condiciones más favorables que Chupícuaro para ocupar una posición ascendente, particularmente en materia de intercambios con las regiones adyacentes. En 1992, Florance (2000, p. 29) considera que los primeros contactos significativos entre las poblaciones preclásicas del valle medio del Lerma y las de la cuenca de México, señalan el inicio de la fase llamada Chupícuaro: esto lo conduce a hacer reajustes en su marco cronológico, pues propone ubicar esta fase en el intervalo 400-150 a.C. Sin dejar de defender la idea de relaciones recíprocas, el autor opina que, durante la fase Chupícuaro, estos contactos fueron intensificándose y tuvieron importantes consecuencias para el valle medio del Lerma. Según Florance (1993, p. 30; 2000, p. 29), los entierros de El Rayo, descubiertos en 1946, reflejarían la naturaleza y la magnitud de este contacto, en particular a través de la aparición de nuevas formas cerámicas ${ }^{12}$. Este mismo autor habría recolectado, durante sus prospecciones en Puruagüita, en los sitios JR 9 y JR 10, algunos tiestos domésticos que serían diagnósticos del Preclásico superior de la cuenca de México (" outflaring rim with an interior channel at or near the lip ", véanse las comparaciones con Vaillant 1931), así como dos fragmentos de figurillas a las que relaciona con el tipo I Chimalhuacan (Florance 1989, pp. 569-571; 2000, p. 29), (Figura 6). Sobre la base de estas evidencias arqueológicas, consideradas como sustanciales, Florance (2000, p. 31) desarrolla un modelo en el cual sugiere que la región de Chupícuaro, en aquel entonces, habría gravitado en la órbita de la cuenca de México, y que las élites locales habrían fortalecido sus posiciones al acceder a la economía de la cuenca de México y al identificarse con el sistema ideológico de sus dirigentes. De esta manera, considera que las vasijas y las figurillas de la cuenca de México se habrían convertido en símbolos manipulados por las élites locales con el objeto de afianzar su estatuto y que determinados sitios de la cuenca habrían fungido como intermediarios entre ambas regiones. En su trabajo de 1993, Florance va aún más lejos, cuando sugiere que las estructuras políticas de la cuenca de México, en particular las de Cuicuilco, podrían haber conducido a la fundación de un asentamiento en la parte oriental del valle de Acámbaro; a este respecto, 


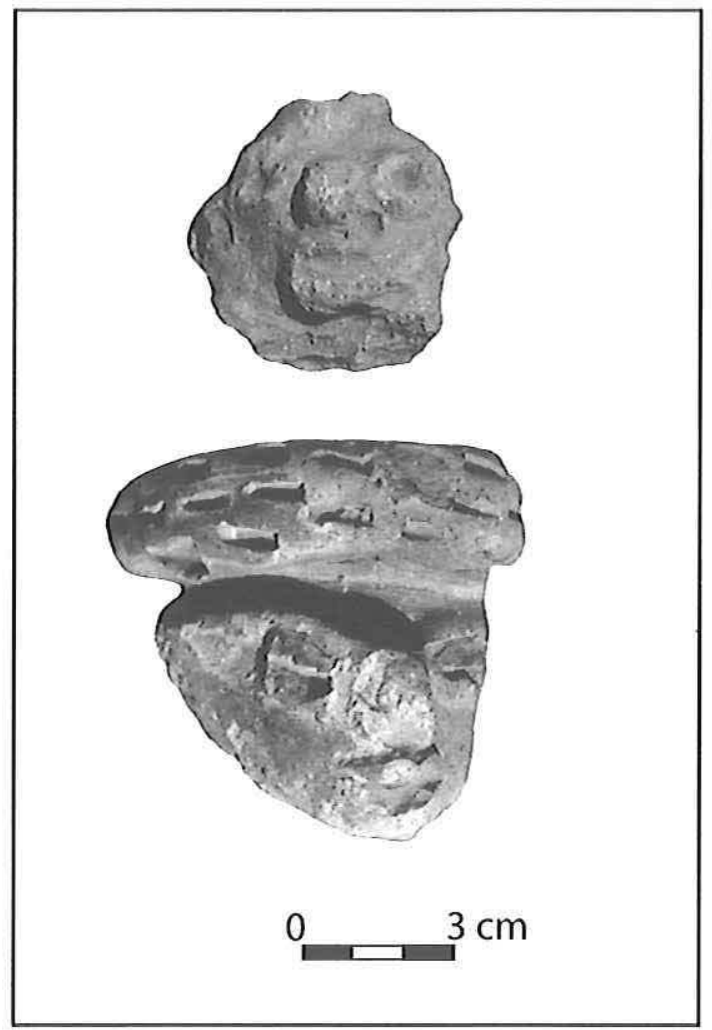

FIG. 6 - Figurillas del tipo I Chimalhuacan, recogidas en recolecciones de superficie en el sitio JR 9 por Florance (según Florance 2000, figura 2.8, p. 30).

menciona los sitios JR 9 y JR 10, cerca de Puruagüita (ibid., p. 30). Paralelamente, la cuenca de México habría experimentado una cada vez mayor dependencia con relación a las producciones cerámicas del valle medio del Lerma: la creciente demanda de recipientes pintados, bicromos y policromos, habría estimulado las producciones locales, generando así un periodo de prosperidad. En el registro arqueológico local, los efectos de esta presión económica se manifestarían a través del surgimiento de nuevos elementos cerámicos, del incremento de las vasijas monocromas (menos codiciadas por la gente de la cuenca de México) y de una disminución general en la calidad de las producciones.

Finalmente, sus comparaciones con las regiones occidentales lo conducen a interrogarse sobre el impacto de la política de Cuicuilco hasta las tierras altas de Jalisco. Para ello evoca la semejanza entre las estructuras circulares con cinco gradas de la fase Arenal (los guachimontones, véase Weigand 1985; 1993; 2000) 
y la arquitectura de Cuicuilco. Como lo acabamos de ver, desde el valle medio del Lerma las posiciones son pues diferentes: describen una preeminencia de la cuenca de México, y en particular de Cuicuilco, sobre Chupícuaro, al mismo tiempo que subrayan la creciente dependencia de esta primera región en relación con la segunda. Si nos adherimos al modelo de Florance (2000, p. 30), podemos imaginar que el impacto de Chupícuaro en la cuenca, mediante la propagación de su estilo dentro de las producciones locales (todo ello durante la fase Chupícuaro, 400-150 a.C., según la cronología de este autor), se habría visto favorecido y reforzado por la distribución masiva de productos manufacturados en un marco fomentado y controlado por las estructuras dirigentes de Cuicuilco. Si bien el enfoque de Florance reviste particular interés, sus argumentos no dejan de prestarse a discusión.

\section{¿Intercambios económicos florecientes?}

De forma paralela a los modelos que pintan movimientos de población o/y influencias de distinta modalidad, se considera simultáneamente Chupícuaro como un centro de producción alfarera que habría difundido a larga distancia sus vasijas y figurillas. Como lo acabamos de ver, las hipótesis de Florance reposan sobre la idea de flujos desigualitarios entre la cuenca de México y el valle de Acámbaro. Por una parte, las estructuras políticas de Cuicuilco, quizá representadas físicamente por grupos de individuos instalados en la parte este del valle de Acámbaro, habrían controlado la distribución de los productos, velando por el abastecimiento de cerámicas bicromas y tricromas, así como de figurillas $\mathrm{H} 4$, en la cuenca de México; por otra, sólo las élites chupicuareñas habrían tenido acceso a ciertos bienes de la cuenca de México.

Con todo, los datos disponibles para las regiones del Centro no parecen dar cuenta de la abundancia subyacente al modelo de Florance. Es cierto que varias publicaciones se refieren a productos que serían resultado de transacciones comerciales. La mayor parte de estos elementos ya han sido ampliamente señalados y discutidos, particularmente por Porter (1956; 1969), luego por McBride (1969). Sin embargo, es preciso hacer hincapié en su número poco elevado: de los 29 lugares citados en el cuadro anexo, sólo 8 habrían arrojado este tipo de indicios. Además, estas interpretaciones generalmente se establecen a partir de apreciaciones subjetivas, sin el apoyo de análisis metódicos de aspectos tecnológicos y petrográficos. Por otra parte, cabe observar que estos indicios nunca aparecen aislados, sino que siempre figuran dentro de colecciones ya emparentadas con la tradición Chupícuaro. En Cuicuilco y en Ticomán, la mayor parte de los recipientes de tradición Chupícuaro serían de fabricación local, mientras que tan sólo algunos podrían resultar realmente de una adquisición comercial: un fragmento negro y rojo sobre bayo en Ticoman (Vaillant 1931, p. 290) (Figura 7), algunos tiestos bicromos blanco sobre rojo en Cuicuilco. Los trabajos de Müller 


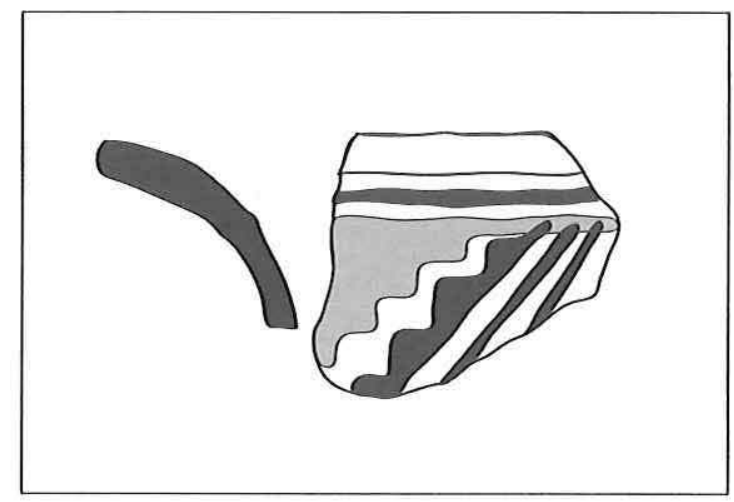

FIG. 7 - Tiesto procedente de Ticoman y considerado como el producto de una transacción comercial con el área de Chupícuaro (redibujado de Vaillant 1931, plate LXXVI, figura i, p. 386).

(1990), por su parte, mencionan la presencia de grupos cerámicos intrusivos, de tradición Chupícuaro, aunque sin precisar si se trata de producciones exógenas o locales. En 1934, las excavaciones de Gualupita, en el Estado de Morelos, brindaron a Vaillant la oportunidad de reafirmar el estrecho parentesco cultural con Chupícuaro. Sin embargo, este autor menciona un solo tiesto, perteneciente a un recipiente rojo sobre bayo, que podría provenir directamente de Chupícuaro (Vaillant 1934, p. 83). Por otra parte, pese a los cambios en las tradiciones cerámicas que habían empezado desde la fase Cuicuilco I, y a la aparición del grupo de figurillas a las que Vaillant denominó $\mathrm{H}$, las figurillas del tipo H4 sólo llegaron a imponerse realmente durante la fase Cuicuilco IV, es decir, entre $200 \mathrm{y}$ 100 a.C. ${ }^{13}$ (Heizer y Bennyhoff 1972, p. 100; Müller 1990, p. 256). Según estos autores, una parte de estas figurillas podría resultar de transacciones comerciales, mientras que otras serían de fabricación local. Por su parte, el sitio de Tlapacoya habría proporcionado vasijas (Figura 8) y figurillas $\mathrm{H} 4$ similares a las de Chupícuaro, que fueron interpretadas como imitaciones locales (Barba de Piña Chan 1956; 1980, p. 88). Sin embargo, ciertas vasijas, consideradas como funerarias, habrían sido importadas directamente de Chupícuaro (ibid., lámina 15). A su vez, McBride (1969, p. 36) afirma que algunas figurillas H4 halladas en Cuauhtitlán están elaboradas en un estilo muy puro, lo cual revelaría sin lugar a dudas que fueron fabricadas en su región de origen. Se trataría de un total de 9 piezas (cuatro cabezas, una grande y dos pequeñas figurillas completas, y dos otros fragmentos - McBride 1974, p. 328), todas procedentes de contextos no controlados (halladas en los montones de desechos producidos por los tabiqueros). Paralelamente menciona otras figurillas de estilo $\mathrm{H} 4,8$ en total, que revelarían más bien una influencia de Chupícuaro (ibid., p. 398). Por otra parte, este autor menciona 4 tiestos recolectados en los niveles fechados del final de la fase 


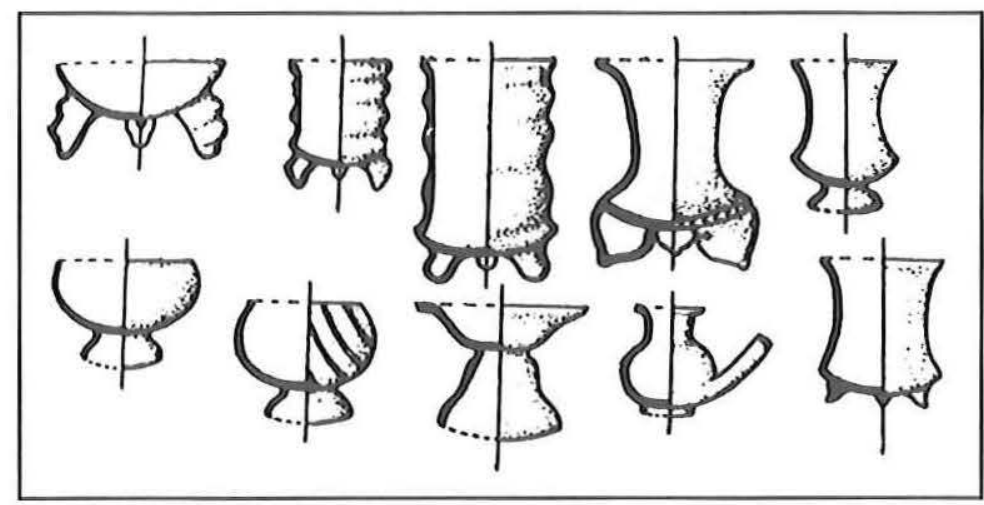

FIG. 8 - Recipientes procedentes de las excavaciones de Tlapacoya que presentan formas de estilo Chupícuaro (según Piña Chan 1956, figura 15).

Cuicuilco III, que podrían resultar de una transacción comercial (ibid., pp. 318319): Figura 9. En Tepejí del Río, Cook de Leonard (1956-1957) señala también la presencia de dos recipientes hallados en un contexto funerario, que podrían proceder de la región de Chupícuaro. En cambio, la ausencia de datos contextuales acerca de los dos recipientes hallados aparentemente en Teotihuacan y mencionados por Linné (Figura 10), no permite establecer inferencias al respecto (citado en McBride 1969). En fechas más recientes, se habrían descubierto en las excavaciones de San Miguel Amantla vestigios cerámicos susceptibles de haberse adquirido mediante intercambio (Castillo Mangas, Córdoba Barradas y García Chávez 1993). Finalmente, el sitio de Cerro El Tepalcate merece particular atención. Situado al oeste de la cuenca, este lugar fue excavado por Piña Chan y Pareyon en 1949, y arrojó elevadas cantidades de tiestos de estilo Chupícuaro (Pareyon 1961). De acuerdo con Porter (1956; 1969), estos tiestos no pueden distinguirse de los que se encuentran en Chupícuaro, lo que nosotros pudimos confirmar después de haber tenido la oportunidad, en 2003, de examinar algunos ejemplares. Pese a un estudio petrográfico de las pastas (Howel 1956, p. 571), no fue posible determinar su origen, aun cuando la hipótesis de Porter, perfectamente plausible, es la de una distribución desde Chupícuaro. Como quiera que sea, este sitio es probablemente en donde las colecciones cerámicas presentan mayores similitudes con Chupícuaro: si éstas no resultan de intercambios comerciales, puede plantearse la posibilidad de una presencia chupicuareña en el sitio. Finalmente, para concluir sobre este punto, cabe señalar que ciertos autores prudentemente precisan que su muestra cerámica portadora de un estilo Chupícuaro evoca una indudable influencia, interrelaciones, o una presencia física in $s i t u$, sin que ello implique relación comercial alguna. Tal es el caso, en particular, para distintos contextos de las regiones de Tlaxcala y Puebla (Guevara Ruiseñor 


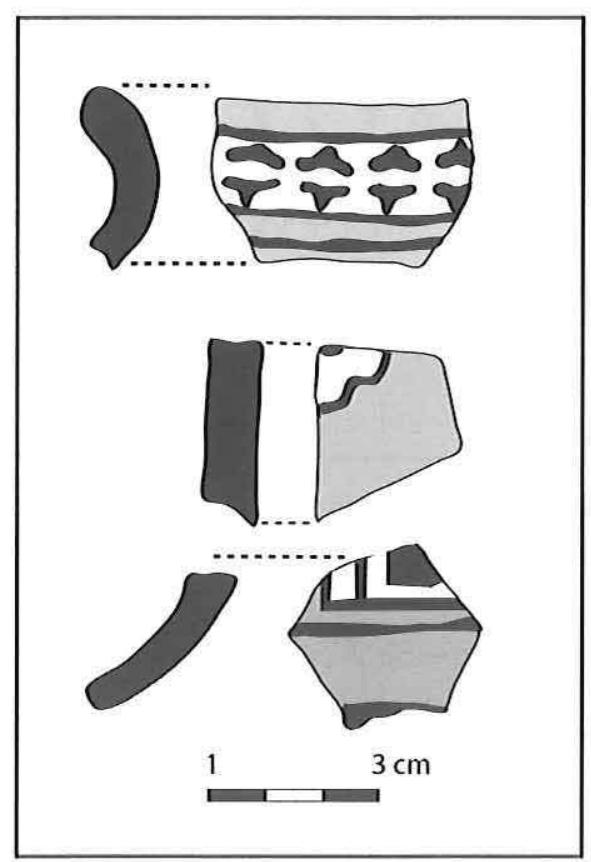

FIG. 9 - Tiestos procedentes de San José Cuauhtitlan fechados de las fases IV y V que podrían ser productos importados desde Chupícuaro (redibujados de McBride 1974, plate 29, p. 289).

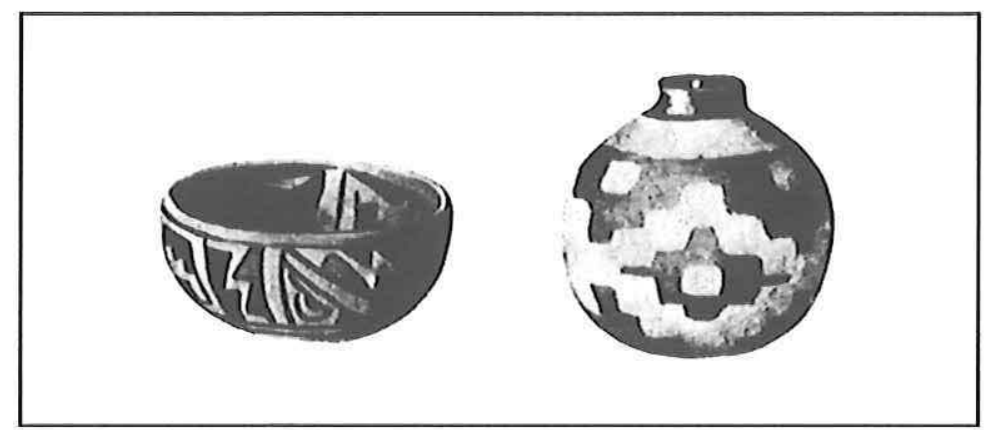

FIG. 10 - Recipientes miniaturas de barro encontrados cerca de Teotihuacan e interpretados como productos importados desde el área de Chupícuaro (Linné 1942, p. 175, reproducido en McBride 1969, p. 36). 
1975; García Cook y Rodríguez 1975). En estas regiones, parece ser que el grupo de figurillas $\mathrm{H}$ se arraiga durante la fase Texoloc (800-300 a.C.) y que la presencia del tipo H4 se afirma durante la fase siguiente (fase Tezoquipan, 300-100 a.C), aunque su estilo es considerado como puro y semejante a los especímenes del valle de Acámbaro (Figura 5).

Las informaciones disponibles hasta $1998^{14}$ en el valle de Acámbaro que podrían sustentar intercambios comerciales son escasas. Ya en 1956, Muriel Porter subrayaba esta carencia de datos relevantes. Sin embargo, si examinamos los materiales procedentes de las excavaciones de 1946, esta autora señala la presencia de algunas figurillas que podrían ser intrusivas y resultar de transacciones. Cuatro de ellas se asemejan al tipo H5 de Vaillant cuya presencia discreta se manifiesta en los niveles correspondientes al final del periodo Ticomán, procediendo dos de ellas de Azcapotzalco. Por otra parte, Muriel Porter (1956, p. 559) les atribuye también alguna semejanza con ciertas figurillas de jadeíta halladas en Teotihuacan.

Con otra perspectiva, si seguimos las hipótesis de Florance, la preeminencia de Cuicuilco en este mismo valle habría permitido a las élites locales tener acceso a productos de prestigio. De acuerdo con las propuestas de este autor (Florance 1993; 2000), el sector de Puruagüita en particular habría ocupado una posición privilegiada debido a su ubicación geográfica. Esta zona habría fungido como interfaz entre el resto del valle y la cuenca de México. Como lo hemos visto, Florance elabora su modelo a partir de las semejanzas de dos fragmentos de figurillas con el tipo I Chimalhuacan ${ }^{15} \mathrm{y}$, a partir de la forma de algunos bordes de tiestos de ollas domésticas, cuya morfología se asemeja a ciertas manifestaciones de la cuenca de México (para las fases Tezoyuca/Chimalhuacan). Sin embargo, estos indicadores materiales merecen ser discutidos.

De hecho, la correspondencia estilística que el autor establece con los tiestos y las figurillas de la cuenca de México, no descansa en un estudio de las pastas o de los acabados, y en consecuencia el autor no está en posibilidades de demostrar que se trata de productos importados o, por el contrario, fabricados localmente. Es por otra parte necesario cuestionarse para saber si la naturaleza misma de estos marcadores (tiestos de ollas burdas no decoradas y dos fragmentos de figurillas) es suficiente para sustentar su idea de que las elites consumían bienes de prestigio y manipulaban símbolos importados para asentar más eficientemente su poder.

En resumen, la escasez de los elementos de comparación demuestra de cuán poca información disponemos para hablar de circulación de recipientes cerámicos o figurillas de la región de Chupícuaro al Centro de México y viceversa. Como se vió, los sitios donde pudo haberse producido este tipo de contacto no son numerosos y las cantidades de tiestos involucrados, con excepción de aquellos del Cerro del Tepalcate, son reducidas. Por lo tanto, cabe preguntarse si estos datos arqueológicos reflejan alguna realidad, a saber, que la circulación de productos 
manufacturados fue poco significativa, o bien si, por motivos de distinta índole, ellos no reflejan la verdadera magnitud de los contactos comerciales. En este sentido, es preciso interrogarse acerca de la pertinencia del criterio de densidad como instrumento de medición del grado de las interacciones económicas e interesarse más en la naturaleza de los objetos. De hecho, aún restaría demostrar que todos estos objetos son efectivamente productos de importación, y no artículos de fabricación local, lo que implicaría vínculos de otra índole.

\section{Las nuevas perspectivas brindadas por el proyecto Chupícuaro}

Los trabajos arqueológicos emprendidos en 1998 en la parte oriental del valle de Acámbaro ofrecen la oportunidad de contribuir nuevamente a las reflexiones en torno a la problemática de los nexos de Chupícuaro con sus vecinos y sobretodo con la cuenca de México. De hecho, algunos datos permiten hoy día matizar o, al contrario, asentar varias de las hipótesis propuestas desde hace cincuenta años ${ }^{16}$. De acuerdo con los postulados de Florance (2000), se podía en particular esperar que el registro arqueológico del sector de Puruagüita tradujera la posición privilegiada de esta zona. No obstante esta espera, hay que constatar que los vestigios materiales recolectados por el proyecto Chupícuaro en esta última área, pero también en el sector de San José Hidalgo, no permiten captar con claridad las modalidades y los efectos de los posibles contactos con la cuenca de México y sus alrededores, por lo menos durante el periodo comprendido entre 400 y 200 a.C. ${ }^{17}$.

En primer lugar, los datos recabados parecen excluir la hipótesis de un avance inicial desde el Centro de México. Las excavaciones no revelaron elementos que remontarían al Preclásico temprano y medio, y eso apoya la hipótesis de un poblamiento tardío de la zona probablemente durante el siglo vi a.C. (Darras y Faugère 2005b). Si bien el origén geográfico de la población no está establecido con certeza, la puesta en evidencia en el valle mismo de una arquitectura monumental de planta circular; en forma de patio hundido, así como de prácticas funerarias que se inscriben en la tradición de las tumbas de tiro (Darras y Faugère 2004; 2005a), sin olvidar las semejanzas estilísticas en la alfarería, nos conduce en establecer un parentezco indudable con las culturas del Occidente (Darras y Faugère s.d.b).

En segundo lugar, en los estratos arqueológicos correspondientes a la primera parte de la fase Chupícuaro reciente (entre 400 y 200 a.C.), no registramos indicadores que nos permitieran evocar intercambios económicos con la cuenca de México. En las colecciones cerámicas, no encontramos vasijas o figurillas que podrían haber sido importadas o que podrían testimoniar de una influencia estilística. Por ejemplo, en la cerámica de factura burda (utilizada para cocer y almacenar), no hallamos tiestos de olla que presentarán los rasgos descritos por Florance (1989, pp. 569-571) y que estuvieran relacionados con tipos de olla de la 
cuenca de México. Por otra parte, y en contra de lo que el observó, la cerámica monócroma fina del sitio JR24 representa una proporción menos elevada que la cerámica decorada (el $5 \%$ contra casi el $10 \%$ de la muestra recogida). Esta superioridad númerica de la cerámica decorada es constante durante toda la fase Chupícuaro reciente y en todos los sitios explorados. En cuanto a las figurillas, las que constituyen la gran mayoria del corpus son del tipo H4. A menos que futuros estudios aporten datos nuevos, la información actual apunta la ausencia de tipos exógenos y se caracteriza por tradiciones estilísticas muy locales. En el ámbito de la industria de obsidiana, observamos una economía dirigida hacia los yacimientos locales, en particular la Sierra de los Agustinos (Estado de Guanajuato: Cruz Jiménez 2005), y una ausencia notoria de navajas prismáticas, presentes no obstante en los contextos correspondientes de Cuicuilco y Ticomán.

En realidad, los primeros indicios que testimonian de contactos no son de tipo comercial, pues conciernen la arquitectura. En 2004, la excavación de una construcción cuadrangular de 22 metros de lado, que forma un patio hundido, permitió hacer observaciones similares a las efectuadas por Castañeda y Cano en el sitio vecino de La Virgen. La introducción del concepto cuatripartita en la arquitectura hacia el fin de la fase Chupícuaro tardío (entre 200 y 100 a.C.), después del uso de plantas circulares, traduce una evolución que podría traducir nuevos contactos y una incorporación más perceptible de los códigos mesoamericanos vigentes en las regiones situadas más al oriente (tal como en Morelos, Tlaxcala, Puebla etc). A partir de 200 a.C., y aunque esto sucedió de un modo paulatino, las poblaciones Chupicuaro aparentemente dejan de edificar patios hundidos circulares en beneficio de patios hundidos cuadrangulares orientados hacia los puntos cardinales (Darras y Faugère 2005b; s.d.b et c). En esta perspectiva, es interesante hacer hincapié que los cambios perceptibles entre 200 y 100 a.C. en el valle de Acámbaro, coinciden con un incremento, en Cuicuilco, pero también en las regiones de Tlaxcala y Puebla, de los elementos propios del estilo Chupícuaro (Heizer y Bennyhoff 1972; Müller 1990; García Cook 1974; García Cook y Rodríguez 1975). Si bien los cambios en la arquitectura constituyen el primer indicio claro de contactos con el Centro de México, los cuales se acentuarán después, hay que esperar la fase Mixtlan (0-250 d.C.) para que se observen verdaderos indicadores de tipo comercial: uno de ellos es la aparición en el valle de Acámbaro de la navaja prismática de obsidiana verde translúcido o gris/negro translúcido ${ }^{18}$ aunque en cantidades muy reducidas.

Con todo, los hallazgos, fruto de las investigaciones recientes en la parte oriental del valle de Acámbaro, aún no han permitido precisar la naturaleza y la amplitud de sus nexos con el Centro de México. En el estado actual de la información, no existen pruebas materiales de contactos comerciales durante la fase Chupícuaro reciente, pero sí durante la fase Mixtlan, o sea a partir del siglo I d.C. En cambio, las transformaciones que afectan la arquitectura a partir de 200 a.C. revelan una evolución profunda de la sociedad chupicuareña, en 
relación probable con los desarrollos culturales contemporáneos del Centro de México.

\section{Conclusiones}

El asunto de las relaciones de Chupícuaro con la cuenca de México y áreas vecinas durante el Preclásico reciente sigue siendo embrollado a causa de numerosas incógnitas. La revisión crítica de los discursos vigentes conduce a adoptar una visión prudente que matiza los modelos propuestos. Para interpretar ciertos vestigios materiales, vimos que esos discursos se refieren, y a veces simultaneamente, a diferentes procesos o nociones: movimientos de población, redes de circulación de productos manufacturados y, más rotondamente, a « influencias », ejercidas en particular en el ámbito de las producciones cerámicas. Más raremente entreven los contactos como dinámicas culturales interactivas. De cierta manera, la diversidad de las propuestas acerca del fenómeno Chupícuaro revela que las modalidades de difusión de sus tradiciones alfareras se dieron por múltiples vías y ritmos, en temporalidades igualmente diferentes, y pueden resultar de la simbiosis de varios factores. La presencia de vestigios cerámicos considerados como " puros » que podrían haber sido importados de Chupícuaro, en sitios ya afiliados a la « tradición » Chupícuaro, ilustra de manera perfecta la diversidad de las escalas de contactos e influencias.

Con todo, la hipótesis emitida en la década de 1960 la cual supone la llegada a Cuicuilco de grupos chupicuareños durante la fase Ticomán I, continúa siendo un modelo explicativo fuerte. En efecto, no está excluido el que, llevado por el impulso de una primera colonización del Bajío, otro flujo, de menos envergadura, habría progresado más lejos, hasta la cuenca de México ${ }^{19}$. En este caso, ambas regiones habrían sido colonizadas por poblaciones de origen común y misma identidad cultural, pero que habrían evolucionado posteriormente para dar paso a expresiones regionales propias. Porque, pese a numerosos rasgos comunes, las tradiciones de cada regíon al parecer presentan diferencias que no pueden confundirlas.

Por otra parte, queda evidente que ciertos productos elaborados en Chupícuaro circularon en la cuenca de México y las regiones circundantes. Es de lamentar que la literatura no refleje adecuadamente las modalidades de esta circulación y que no estemos en condiciones de evaluar su magnitud real. La intrusión más clara de elementos « Chupícuaro », tales como las figurillas H4 a partir de la fase Cuicuilco IV, es decir, entre 200 y 100 a.C., podría corresponder a un incremento de las interacciones de tipo económico. Por su parte, la aparición de navajas prismáticas verdes en el valle de Acámbaro durante la fase Mixtlan (0-250 d.C.) podría corroborar este modelo. Finalmente, la distribución de productos Chupícuaro en los sitios de la fase Ticomán podría también haber 
suscitado procesos de imitación y dado lugar a un fenómeno de moda, el cual se habría traducido en la progresiva propagación de elementos estilísticos Chupícuaro dentro de las producciones locales, alentando finalmente la conformación de un estilo propio.

A finales de cuenta, para tratar de abordar de manera rigurosa el problema de las relaciones de Chupícuaro con el centro de México, en un plan tanto economíco como ideológico, o a través de movimientos de población, es, por supuesto, indispensable precisar el marco cronológico, y cerciorarse - en particular mediante estudios tecnológicos y análisis petrográficos y geoquímicos de las pastas y pigmentos - de que las muestras cerámicas en cuestión corresponden a intercambios comerciales o producciones locales. Si queda indispensable que el registro arqueológico arroje nuevos elementos para mejorar nuestra visión del problema, estamos seguros de que el corpus puede producir más información. Pero eso sólo puede concebirse mediante una revisión metódica que permita asentar bases de comparación firmes, en particular a través de la aplicación de parámetros de descripción úniformes, la puesta en consideración síncrona de los demás aspectos de la cultura material, y un examen directo y sistemático de las diferentes colecciones. En definitiva, las diferentes eventualidades examinadas en este artículo apoyan la idea según la cual los grupos que vivían en el Centro-Norte de México gozaron de especial renombre por su producción cerámica. Las excepcionales productividad y creatividad de los alfareros chupicuareños, aunadas a la selección de colores específicos, habrían desembocado en la conformación de un repertorio estilístico particularmente rico, acabado y personalizado. *

* Manuscrit reçu en novembre 2005, accepté pour publication en juin 2006.

\section{NOTAS}

1. En el presente trabajo, los términos « cultura Chupícuaro », " complejo Chupícuaro » o « Chupícuaro » a secas se refieren exclusivamente a los desarrollos culturales del periodo Preclásico reciente, en la región del valle medio del Lerma, y del centro-norte en general (región de Ucareo, Querétaro). En cambio, usamos el término " tradición » o " estilo Chupícuaro » para designar conjuntos cerámicos que fueron hallados en otras partes, a veces de otros periodos, pero que se inscriben dentro de un concepto estilístico que recuerda, en distintos grados, los materiales cerámicos elaborados en las regiones arriba mencionadas.

2. En las nuevas investigaciones que se vienen desarrollando desde 1998, nos vemos confrontados, en cada temporada, a la extrema complejidad de los contextos estratigráficos correspondientes a la ocupación Chupícuaro. No resulta, pues, sorprendente, que los métodos de exploración que se aplicaron hace casi 60 años, no hayan permitido una interpretación óptima de la estratificación.

3. Centro de Estudios Mexicanos y Centroamericanos en México. El proyecto Chupícuaro cuenta con financiamiento del centro Nacional de la Investigación Científica (CNRS, Paris) y del Ministerio de los Asuntos Exteriores. Es dirigido por Véronique Darras y Brigitte Faugère. 
4. Los últimos trabajos realizados por el CEMCA permiten ahora ubicar los inicios de esta fase a principios de la era y su fin hacia 250 d.C. (Darras y Faugère s.d.c).

5. Actualmente, existen nuevos proyectos en Tlaxcala y Puebla que reafirman las observaciones hechas en los años 1970 acerca de similitudes estilisticas con el centro-Occidente. Ver por ejemplo los trabajos realizados actualmente en el marco del proyecto (UCLA) « Investigaciones del Formativo en la región de Apizaco, Tlaxcala » dirigido por Richard Lesure.

6. Nótese que los 13 sitios « Tezoyuca » se agrupan aquí en una sola unidad.

7. Por ejemplo, Jonathan Guevara Ruiseñor $(1975$, p. 146) publicó un mapa de la región PueblaTlaxcala, el cual comprende 62 sitios arqueológicos que estarían relacionados con las culturas del Occidente, durante las fases Texoloc, Tezoquipan y Tenanyecac, es decir, entre 800 a.C. y 650 d.C.. Sin embargo, este autor no aporta precisión alguna en cuanto a la temporalidad, la naturaleza de los vínculos y la región precisa con la cual se habrian establecido tales vínculos.

8. Charles Florance es uno de los muy pocos autores que discutieron la pertinencia de los modelos propuestos, poniendo en tela de juicio sus primeras hipótesis de trabajo. Desafortunadamente, sus revisiones conceptuales siempre se apoyaron en el mismo corpus arqueológico.

9. Esta intrusión sería perceptible a través de una cerámica incisa sin soporte roja sobre amarillo, y de las figurillas de tipo $\mathrm{E}$ (Heizer y Bennyhoff 1972, p. 99).

10. Los arqueólogos que trabajan actualmente en la región de Tula, Osvaldo Sterpone y Juan Carlos Equihua, dicen no haber logrado identificar este tipo de evidencia.

11. En realidad, el artículo publicado en 2000 fue redactado en 1992 y presenta ideas que Florance retomó, precisándolas, en su trabajo de 1993. Por consiguiente, para seguir la evolución del pensamiento de Florance es necesario respetar la cronología de sus escritos, y no las fechas de sus publicaciones.

12. Estos nuevos elementos cerámicos serían, entre otros: los soportes mamiformes, las bases anulares, las bases en forma de pedestal, los recipientes cilíndricos y los recipientes compuestos así como, por supuesto, la categoría de figurilla $\mathrm{H} 4$.

13. Sin embargo, Müller (1990, p. 256) señala la presencia de figurillas de gran tamaño del tipo $\mathrm{H} 4$.

14. Fecha en que iniciaron los trabajos de campo del proyecto Chupicuaro (CEMCA/CNRS). hueco.

15. En realidad, una de estas "figurillas » parece ser un fragmento de soporte antropomorfo

16. Un artículo sobre el tema de los nexos de Chupicuaro con sus vecinos, con un enfoque particular hacia las aportaciones recientes de nuestros trabajos arqueológicos, está actualmente en prensa (Darras y Faugère s.d.b).

17. Los trabajos arqueológicos y numerosos fechamientos radiocronométricos han permitido precisar el marco cronológico y proponer las divisiones siguientes: fase Chupícuaro temprano (600400 a.C.), fase Chupícuaro reciente ( $400-100$ a.C.), fase de transición (100 a.C.- 0 ), fase Mixtlan (0-250 d.C.). De acuerdo con nuevos hallazgos, la fase Chupícuaro reciente pudo ser subdivida en dos subfases (400-200 a.C. y 200-100 a.C.) (Darras y Faugère 2005b; s.d.b y c).

18. La obsidiana verde proviene del Cerro de las Navajas, Pachuca. El origen de la variedad gris/negro aún no ha sido determinado.

19. Si estas poblaciones hubiesen transitado por el valle de Toluca, sería de suponerse que habrian dejado huellas de su paso. Sin embargo, González de la Vera observa en este valle una baja demográfica significativa durante la fase Ticomán. En cambio, dicho tránsito podria haberse realizado más al norte, en la región de Tepeji del Río y Tula. 


\section{REFERENCIAS BIBLIOGRAFICAS}

Arnauld Marie-Charlotte, Marie-France Fauvet-Berthelot y Patricia Carot 1993 Arqueología de las Lomas en la cuenca lacustre de Zacapu, Michoacán, México, CEMCA, Cuadernos de Estudios Michoacanos, 5, México.

BARBa de Piña Chan Beatriz

1956 " Tlapacoya: un sitio preclásico de transición », Acta antropológica, epoca 2, I (1), pp. 1-204, México.

1980 Tlapacoya. Los principios de la teocracía en la cuenca de México, Biblioteca enciclopédica del Estado de México, México.

BeLL Betty

1974 The archaeology of West México, Sociedad de estudios avanzados del Occidente de México, Ajijic, Jalisco.

Bennyhoff James A.

1966 "Chronology and periodization: continuity and change in the Teotihuacan ceramic tradition ", Teotihuacan-XI mesa redonda, Sociedad mexicana de antropología, México, pp. 19-29.

\section{BRANIFF Beatriz}

1965 Investigaciones arqueológicas en Guanajuato, México: consideraciones preliminares, mecanoscrito, Museo Nacional de Antropología, México.

1972 "The West Mexican tradition and the Southwestern United States », The Kiva, 41 (3), pp. 215-222, Arizona Archaeological and Historical Society, Tucson.

1996 "Los cuatro tiempos de la tradición Chupícuaro », Arqueología, segunda época, 16, pp. 113-143, INAH, México.

1998 Morales, Guanajuato, y la tradición Chupícuaro, INAH, colección científica 373, México.

2000 "A summary of the archaeology of North-Central Mesoamerica: Guanajuato, Querétaro and San Luis Potosí ", in Michael S. Foster y Shirley Gorenstein (eds), Greater Mesoamerica. The archaeology of West and Northwest Mexico, University of Utah Press, Salt Lake City, pp. 3542.

\section{Carot Patricia}

« La cerámica protoclásica del sitio de Loma Alta, Zacapu, Michoacán », in Brigitte Boehm de Lameiras y Phil Weigand (eds), Origen y desarrollo de la civilización en el Occidente de México, Colegio de Michoacan, Zamora, pp. 69-101.

1993 "Cerámica, otros objetos, complejo Loma Alta ", in Marie-Charlotte Arnauld, Patricia Carot y Marie-France Fauvet-Berthelot, Arqueologia de las Lomas en la cuenca lacustre de Zacapu, Michoacán, México, CEMCA, Cuadernos de Estudios Michoacanos, 5, pp. 156-158, México. 
Le site de Loma Alta, Lac de Zacapu, Michoacan, Mexique, BAR international series 920, Monographs in American archaeology 9, Paris.

Castañeda Carlos, Ana María Crespo y Luz María Flores

1996 "Santa María del Refugio. Una ocupación temprana con reocupación teotihuacana en el Bajío ", in Ana María Crespo y Carlos Viramontes (eds), Tiempo y territorio en arqueología: el Centro-Norte de México, INAH, colección científica 323, México, pp. 161-178.

Castañeda Carlos y Yolanda Cano Romero

1993 «Los túmulos funerarios de Chupícuaro. El caso de La Vírgen, Guanajuato ", Cuadernos de Arquitectura Mesoamericana, 25, pp. 23-28, UNAM, Facultad de arquitectura, México D.F.

Castillo Mangas María Teresa, Luis Córdoba Barradas y Raul García Chávez 1993 "Una aldea del Formativo en San Miguel Amantla, Azcapotzalco », in María Teresa Castillo Mangas (ed.), A propósito del Formativo, Subdirección de salvamento arqueológico/INAH, México, pp. 59-71.

Contreras Ramírez José Antonio y María Teresa Durán Anda

1982 Informe general de la temporada de campo: octubre de 1981-febrero 1982. Proyecto Gasoducto tramo Salamanca-Yuriría, Archivo técnico de la dirección de arqueología, INAH, México.

COOK de LeONARD Carmen

1956-1957 «Algunos antecedentes de la cerámica tolteca 》, Revista mexicana de estudios antropológicos, XIV, pp. 37-43, México.

Covarrubias Miguel

1943 "Tlatilco, archaic Mexican art and culture ", Dyn. The review of modern art, 4-5, pp. 40-46, México.

1950 "Tlatilco: el arte y la cultura preclásica del valle de México », Cuadernos americanos, 3, pp. 149-162, México.

1957 Indian art of Mexico and Central America, Alfred A. Knopf, New York.

Crespo Ana María

1991 "Variantes del asentamiento en el Valle de Querétaro. Siglos I a X d.C. ", in Ana María Crespo y Rosa Brambila (eds), Querétaro prehispánico, INAH, colección científica 238, México, pp. 99-135.

1992 «Unidades político-territoriales », in Brigitte Boehm de Lameiras y Phil Weigand (eds), Origen y desarrollo de la civilización en el Occidente de México, Colegio de Michoacan, Zamora, pp. 157-176.

Crespo Ana María y Carlos Castañeda

1979 Proyecto atlas arqueológico del Estado de Guanajuato, México, Archivo del centro regional Guanajuato del INAH, México, Mecanoescrito.

CruZ Jiménez Ricardo L.

2005 «Aspectos generales de historia y arqueología de la sierra de los Agustinos, Guanajuato ", in Walburga Wiesheu y Patricia Fournier (eds), Perspectivas de la investigación arqueológica. IV coloquio de la maestría en arqueología, ENAH, México, pp. 123-130. 
Cummings Byron

1933 "Cuicuilco and the archaic culture of Mexico », Social science bulletin, IV (4 y 8), pp. 1-56, University of Arizona, Tucson.

Darras Véronique, Brigitte Faugère, Christophe Durlet, Catherine Liot, Javier ReveLES, Oscar CERVANTES Y Cybèle DAVID

1999 "Recherches récentes sur la culture chupicuaro, Guanajuato », Journal de la Société des Américanistes, 85, pp. 343-352.

DARras Véronique y Brigitte Faugère

2001 Informe sobre los trabajos realizados durante los meses de enero, marzo y abril de 2001 en la región de Puruagüita, municipio de Jerécuaro, Guanajuato, CEMCA, Archivo del INAH, México.

2002 Informe sobre los trabajos realizados durante los meses de febrero y marzo de 2002 en la región de Puruagüita, municipio de Jerécuaro, Guanajuato, CEMCA, Archivo del INAH, México.

2003 Informe sobre los trabajos de prospección realizados durante el mes de marzo de 2003 en la región de la presa Solis, Guanajuato, CEMCA, Archivo del INAH, México.

2004 Informe sobre los trabajos realizados durante los meses de febrero y marzo de 2004 en el sitio TR6, Tarandácuao, Guanajuato, CEMCA, Archivo del INAH, México.

2005a Informe sobre los trabajos realizados durante los meses de febrero y marzo de 2005 en el sitio TR6, Tarandácuao, Guanajuato, CEMCA, Archivo del INAH, México.

2005b «Cronología de la cultura Chupícuaro: secuencia estratigráfica y fechamientos radiocronométricos del sitio La Tronera, Puruagüita, Guanajuato ", in Phil Weigand, David Grove y Eduardo Williams (eds), El Occidente de México y el Mundo Mesoamericano: muevos datos, futuras direcciones, Colegio de Michoacan, Zamora, pp. 255-282.

s.d.a «Una manifestación precoz del patrón arquitectónico en forma de patio hundido en la región de Chupícuaro, Estado de Guanajuato (cultura Chupícuaro, 600 a.C.-200 d.C.) ", Arquitectura y urbanismo. Pasado y presente de los espacios en Teotihuacan. Tercera mesa redonda de Teotihuacan, México, INAH, Memoria de la Tercera mesa redonda de Teotihuacan, México [en prensa].

s.d.b «Chupícuaro, entre Occidente y Altiplano central. Balance de los conocimientos y nuevas aportaciones ", in Brigitte Faugère (ed.), Dinámicas culturales entre el Occidente, el Centro-Norte y la cuenca de México del Preclásico al Epiclásico: trabajos recientes, CEMCA/Colegio de Michoacán, México [en prensa].

s.d.c « Reacomodos culturales en el valle de Acámbaro a final del Formativo: la fase Mixtlan y su significado a nivel local y global », in Laura Solar (ed.), El eje Lerma-Santiago durante el Formativo terminal y Clásico temprano: precisiones cronológicas y dinámicas culturales, INAH, México [en prensa]. 


\section{Faugère Brigitte, Véronique Darras y Christophe Durlet}

2000 The Chupicuaro exploitation of hydrothermal resources, México (600 b.c.200 a.d.): geochemical and mineralogical identification and correlation with the archaeological remains, CD ROM Memories Archaeometry Symposium, May 15-19 2000, Mexico City.

Fletcher Charles C.

1963 Cuanalan: an archaeological excavation and study of a Ticoman period site in the valley of Teotihuacan, Estado de México, México, unpublished master's thesis, department of sociology and anthropology, Pennsylvania State University, University Park.

Florance Charles A.

1985 "Recent work in the Chupicuaro region ", in Michael S. Foster y Phil Weigand (eds), The archaeology of West and Northwest Mesoamerica, Westview Press, Boulder, pp. 9-45.

1989 A survey and analysis of late and terminal Preclassic settlement along the Lerma river in Southeastern Guanajuato, Mexico, Ph. Dissertation, Columbia University, New York.

2000 «The late and terminal Preclassic in Southeastern Guanajuato: heartland or periphery? ", in Michael S. Foster y Shirley Gorenstein (eds), Greater Mesoamerica. The archaeology of West and Nortwest Mexico, University of Utah Press, Salt Lake City, pp. 21-34.

s.d. $\quad$ The Preclassic in Southeastern Guanajuato and observations on relationships with the Basin of México and West México ", ponencia presentada para el seminario Perspectivas sobre la arqueología de la periferia septentrional de Mesoamérica, 20-27 de noviembre de1993, Consejo Nacional para la Cultura y las Artes, INAH, Zacatecas.

García COOK Angel

1974 "Una secuencia cultural para Tlaxcala », Comunicaciones, 10, Proyecto Puebla-Tlaxcala, Fundación alemana para la investigación científica, Puebla, México pp. 5-22.

Garcia CoOk Angel y Felipe Rodríguez

1975 "Excavaciones arqueológicas en "Gualupita las Dalias, Puebla" ", Comunicaciones, 12, Proyecto Puebla-Tlaxcala, Fundación alemana para la investigación científica, Puebla, México, pp. 1-8.

\section{GoRENSTEIn Shirley}

1985 Acambaro: frontier settlement on the Tarascan-Aztec border, Vanderbilt University, Publications in anthropology 32, Nashville, Tennessee.

Guevara Ruiseñor Jonathan

1975 «Presencia de las culturas del Occidente de México en la región de Tlaxcala », XII mesa redonda, Arqueología, I, pp. 159-169, Sociedad mexicana de antropología, Xalapa. 
HAURY Emil W.

1945 "The problem of contacts between the Southwestern United States and Mexico ", Southwestern Journal of Anthropology, I (1), pp. 55-74, Albuquerque.

1976 The Hohokam, desert farmers and craftmen. Snaketown. 1964-1965, University of Arizona Press, Tucson.

Healan Dan y Christine Hernández

1999 «Asentamiento prehispánico y cronología cerámica en el Noreste de Michoacán ", in Eduardo Williams y Phil Weigand (eds), Arqueología y etnohistoria. La región del Lerma, El colegio de Michoacán, Zamora, pp. 133-155.

Heizer Robert F. y James A. BennyhorF

1958 "Archaeological investigations of Cuicuilco, valley of Mexico ", Science, 127 (3292), pp. 232-233.

1972 "Archaeological investigations at Cuicuilco, Mexico », National geographic society research reports, 1955-1960 projects, pp. 93-104.

HERnÁNDEZ Christine

2001 "Una comparación entre la fase Perales en el Noreste de Michoacán y la fase Lerma en Acámbaro, Guanajuato ", Arqueología, 25, pp. 23-46.

Howel Williams

1956 "Petrographic notes on tempers of pottery from Chupicuaro, Cerro del Tepalcate and Ticoman ", Transactions of the American philosophical society, 46 (5), pp. 576-580.

Jimenez Peter

1995 «Algunas observaciones sobre la dinámica cultural de la arqueología de Zacatecas ", in Barbara Dahlgreen y María Dolores Soto de Arechaveleta (eds), Arqueología del Norte y del Occidente de México. Homenaje al Dr. J. Charles Kelley, IIA-UNAM, México, pp. 35-66.

LINNÉ Sigvald

1942

" Mexican Highlands cultures », Ethnographical Museum of Sweden, new series, 7, Stockholm.

Manzanilla Linda

1985 «El sitio de Cuanalán en el marco de las comunidades pre-urbanas del valle de Teotihuacán ", in Jesús Monjarráz, Emma Perez Rocha y Rosa Brambila (eds), Mesoamérica y el Centro de México, una antología, INAH, México, pp. 133-178.

McBride Harold W.,

1969 "The extent of the Chupicuaro tradition », in Jay D. Frierman (ed.), The Nathalie Wood Collection of Precolumbian Ceramics from Chupicuaro, Guanajuato, México, UCLA, occasional papers of the Museum and Laboratories of Ethnic Arts and Technology (1), Los Angeles, pp. 33-49.

1974 Formative ceramics and prehistoric settlement patterns in the Cuauhtitlan region, Mexico, Ph. Dissertation, University of California, Los Angeles. 
1977 "The cultural ecology of Formative Cuauhtitlan, Valley of Mexico », Los procesos de cambios (en Mesoamerica y áreas circumvecinas), XV mesa redonda, Sociedad mexicana de antropología y Universidad de Guanajuato, México, pp. 385-396.

Mena Ramón y Porfirio Aguirre

1927 "La nueva zona arqueológica, Chupícuaro, Guanajuato ", Revista mexicana de estudios históricos, 1 (2), pp. 55-64, Sociedad mexicana de antropología, México.

MüLLER Florence

1990 La cerámica de Cuicuilco b: un rescate arqueológico, INAH, colección científica 186, México.

NALDA Enrique

1978 Proyecto Lerma medio. Sector Salvatierra-Acámbaro. Reporte $n^{o} 1$. Mecanuscrito, Archivo del centro regional de Guanajuato, INAH, México.

1979 Proyecto Lerma medio. Sector Yuriria. Reporten ${ }^{\circ}$ 3. Mecanuscrito, Archivo del centro regional de Guanajuato, INAH, México.

1981 Proyecto Lerma medio. Sección Salvatierra-Acámbaro. Reporte n ${ }^{\circ} 3$. Mecanuscrito, Archivo del centro regional de Guanajuato, INAH, México.

Niederberger Christine

1976 Zohapilco. Cinco milenios de ocupación humana en un sitio lacustre de la cuenca de México, INAH, colección científica 30, México.

1986 Paléopaysages et archéologie pré-urbaine du bassin de Mexico, CEMCA, collection Études mésoaméricaines I-II (1), México.

Noguera Eduardo

1935 "Antecedentes y relaciones de la cultura teotihuacana », El México antiguo, 3, pp. 5-8.

1943 "Excavaciones en el Tepalcate, Chimalhuacan, México », American Antiquity, 9 (1), pp. 33-43.

PAREYON Eduardo

1961 Excavaciones en la zona arqueológica de cerro del Tepalcate, San Rafael Chamapa, Estado de México, tesis en arqueología, INAH, México.

Piña Chan Roman

1956 "Excavaciones arqueológicas en el Estado de Morelos », Revista mexicana de estudios antropológicos, XIV, pp. 121-124, México.

Piña Chan Roman, Arturo Romano y Eduardo Pareyon

1952 "Tlatilco: nuevo sitio preclásico del valle de México », Tlatoani, 1 (3-4), pp. 9-14, México.

Plancarte y Navarrete Francisco

1911 Tamoanchan, el Estado de Morelos y el principio de la civilización, [s. n.], México. 
PORTER NOÉ Muriel

1956 "Excavations at Chupicuaro, Guanajuato, Mexico ", Transactions of the American philosophical society, 46 (5), pp. 515-637, Philadelphia.

Porter Weaver Muriel

1969 "A reappraisal of Chupicuaro ", in Jay D. Frierman (ed.), The Nathalie Wood Collection of Precolumbian Ceramics from Chupicuaro, Guanajuato, México, UCLA, occasional papers of the Museum and Laboratories of Ethnic Arts and Technology (1), Los Angeles, pp. 5-15.

Perlstein Pollard Helen

1985 "Lerma river basin survey », in Shirley Gorenstein (ed.), Acambaro: settlement on the Tarascan-Aztec border. Apendix II, Vanderbilt University, Publications in anthropology 32, Nashville, Tennessee, pp. 153-206.

RATTRAY Evelyn

1963 The Preclassic ceramics of Rancho La Cañada, Tenayuca, Universidad las Americas, México, Mecanoescrito.

Reyna Robles Rosa Ma.

1971 Las figurillas preclásicas, tesis de licenciatura en arqueología, ENAH, México.

Saint Charles Zetina Juan Carlos

1996 "El reflejo del poder teotihuacano en el sur de Guanajuato y Querétaro », in Ana María Crespo y Carlos Viramontes (eds), Tiempo y territorio en arqueología. El Centro-Norte de México, INAH, colección científica 323, México, pp. 143-160.

1998 "Los problemas para la identificación del Bajío y la secuencia de San Juan del Río ", in Rosa Brambila y Rubén Cabrera (eds), Los ritmos de cambio en Teotihuacan: reflexiones y discusiones de su cronología, INAH, colección científica 366, México, pp. 335-346.

Saint Charles Zetina Juan Carlos y Miguel Argüelles Gamboa

1991 "Cerro de la Cruz. Persistencia de un centro ceremonial ", in Ana María Crespo y Rosa Brambila (eds), Querétaro prehispánico, INAH, colección científica 238, México, pp. 57-98.

SÁnchez Correa Sergio y Gabriela ZePEDA

1981 Proyecto arqueológico Gasoducto Guanajuato. Tramo SalamancaDegollado. Informe correspondiente a la primera fase de campo, México, Departamento de salvamento del INAH, Archivo del Centro Regional Guanajuato del INAH, México.

1982a Proyecto arqueológico Gasoducto Guanajuato. Tramo SalamancaDegollado. Informe correspondiente a la segunda fase de campo, México, Departamento de salvamento del INAH, Archivo del Centro Regional Guanajuato del INAH, México.

1982b Informe de la temporada de laboratorio del proyecto Gasoducto Guanajuato. Tramo Salamanca-Degollado, México, Departamento de salvamento del INAH, Archivo del Centro Regional Guanajuato del INAH, México. 


\section{SAniders William T., Jeffrey R. Parsons y Robert S. SANtLey}

1979 The Basin of Mexico. Ecological processes in the evolution of a civilization. Studies in archaeology, Academic Press, Inc., New York.

\section{SCHÖNDUBE Otto}

1987 «El Occidente de México: algunas de sus características y problemas », in Brigitte Dahlgren et al. (eds), Homenaje a Roman Piña Chan, UNAM-IIA, México, pp. 403-410.

1988 "Chupícuaro: origen de la tradición Norcentral de México », in Ernesto de la Torre Villar (ed.), Arqueología e historia guanajuatense. Homenaje a Wigberto Jiménez Moreno, Colegio del Bajío, León, Guanajuato, pp. 117 136.

SNARKIS Michael

1985 "Ceramic analysis », in Shirley Gorenstein (ed.), Acambaro: frontier settlement on the Tarascan-Aztec border, Vanderbilt University, Publications in anthropology 32, Nashville, Tennessee, pp. 207-298.

\section{Tesch Mónica}

1977 "Figurillas de Acatepec, Puebla », Comunicaciones, 14, Proyecto PueblaTlaxcala, Fundación alemana para la investigación científica, Puebla, México pp. 87-90.

Tolstoy Paul S., Suzanne K. Fish, Martin W. BoKsenbaum, Blair K. Vaughn y Earle C. SмIтH

1977 «Earliest sedentary communities of the basin of Mexico. A summary of recent investigation ", Journal of field archaeology, 4, pp. 91-106.

Tolstoy Paul S. y Louise I. PARAdis

1970 "Early and middle preclassic culture in the basin of Mexico ", Science, 167 , pp. 344-351.

Trejo Elia C.

1975 "Figurillas características de la secuencia cultural de Tlaxcala », XII mesa redonda, Arqueología, I, pp. 147-157, Sociedad mexicana de antropología, Xalapa.

VAILLANT George C.

1930 "Excavations at Zacatenco ", Anthropological papers of the American Museum of natural history, 32 (1), pp. 1-200, New York.

1931 "Excavations at Ticoman 》, Anthropological papers of the American Museum of natural history, 32 (2), pp. 201-451, New York.

1934 "Excavations at Gualupita », Anthropological papers of the American Museum of natural history, 35 (1), pp. 1-135, New York.

1938 "A correlation of archaeological and historical sequences in the Valley of México ", American anthropologist, 40 (4), pp. 535-573.

WEIGAND Phil

1985 «Evidence for complex societies during the Western Mesoamerican Classic period ", in Michael S. Foster y Phil Weigand (eds), The archaeology of West and Northwest Mesoamérica, Westview Press, Boulder, pp. 47-91. 
1993 Evolución de una civilización prehispánica: arqueología de Jalisco, Nayarit y Zacatecas, El Colegio de Michoacán, Zamora.

2000 "The evolution and decline of a core of civilization: the Teuchitlan tradition and the archaeology of Jalisco ", in Michael S. Foster and Shirley Gorenstein (eds), Greater Mesoamerica. The archaeology of West and Northwest Mexico, University of Utah Press, Salt Lake City, pp. 43-58.

West Michael

1965

"Transition from Preclassic to Classic at Teotihuacan », American Antiquity, 31, pp. 193-202. 


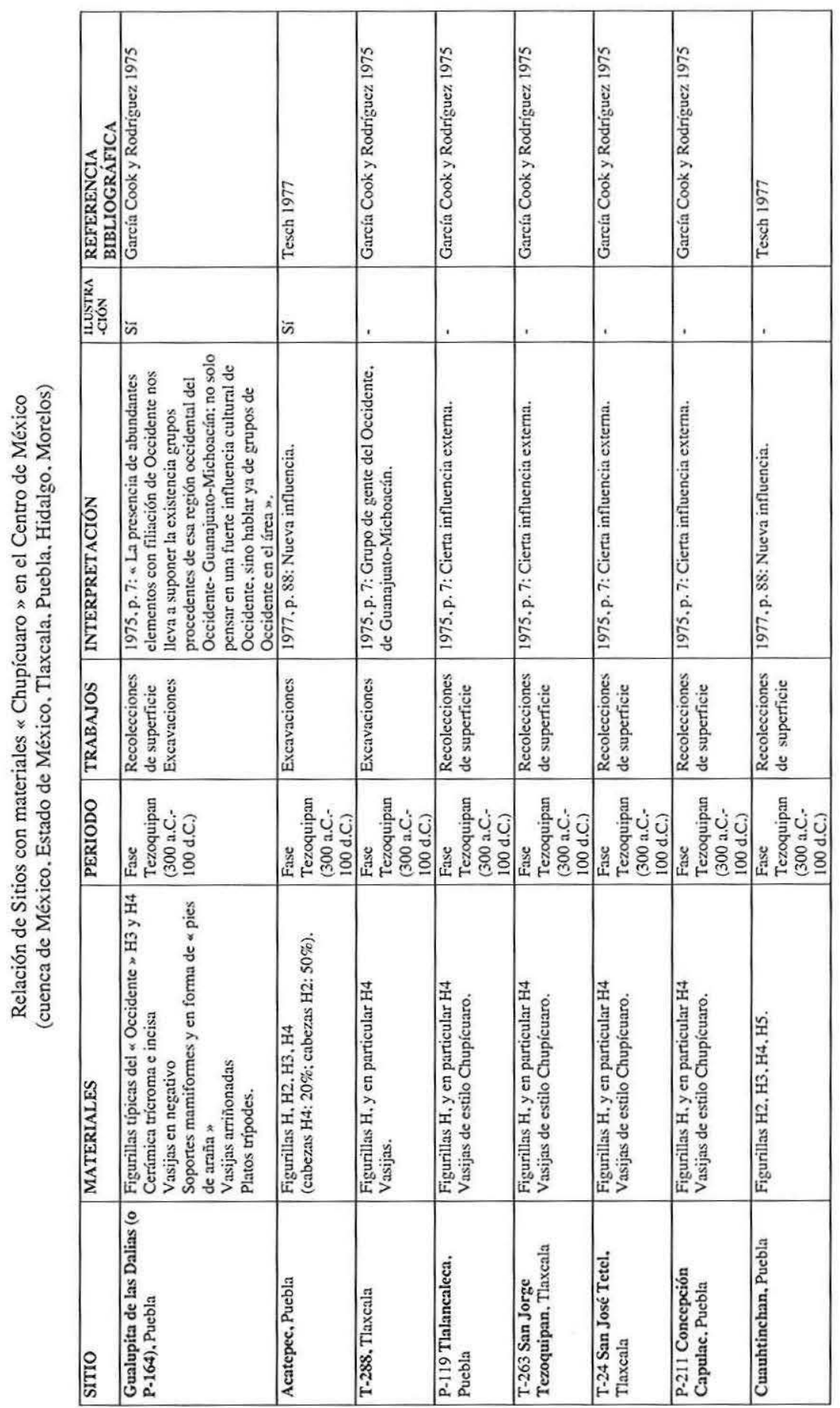




\begin{tabular}{|c|c|c|c|c|}
\hline 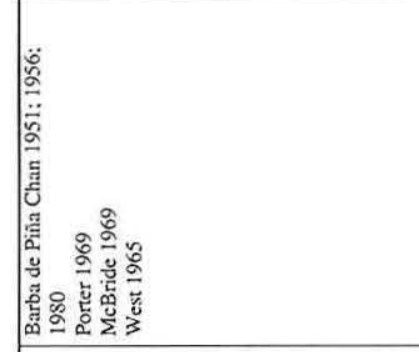 & 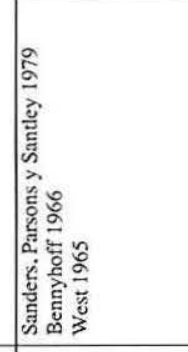 & 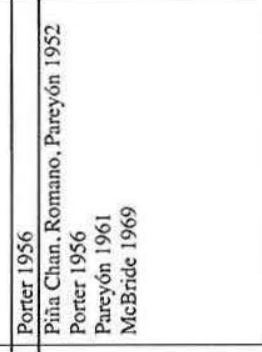 & 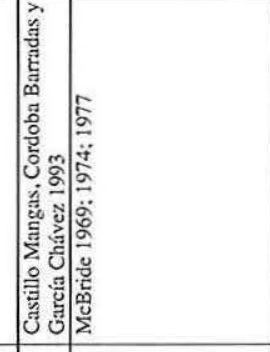 & 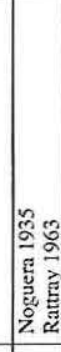 \\
\hline in & & & . 1 in & \\
\hline 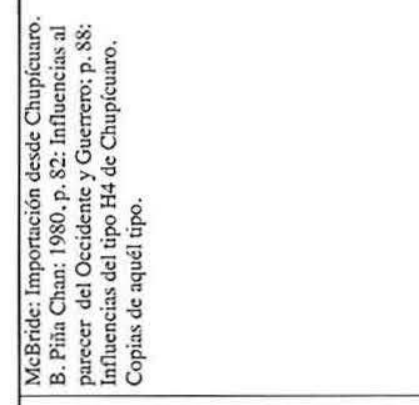 & 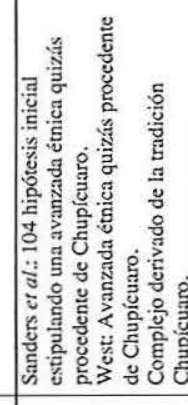 & 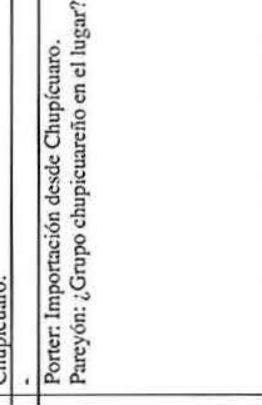 & 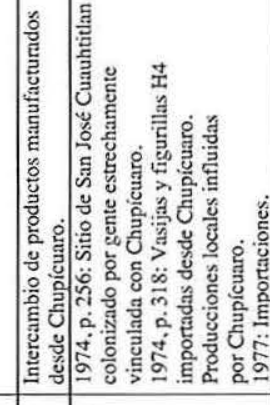 & \\
\hline 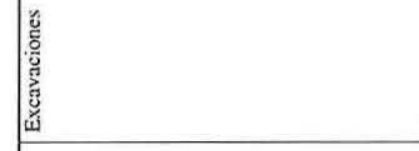 & 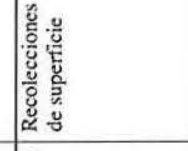 & , & 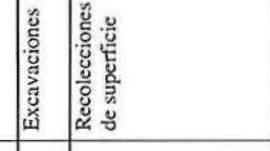 & \\
\hline 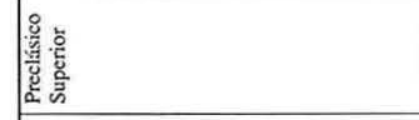 & 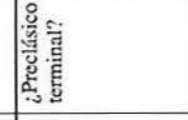 & . & 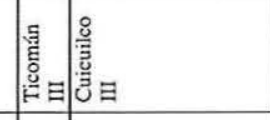 & . \\
\hline 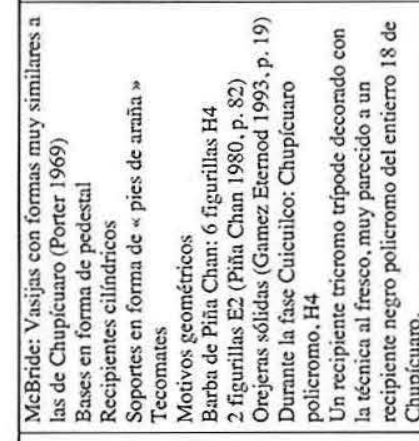 & 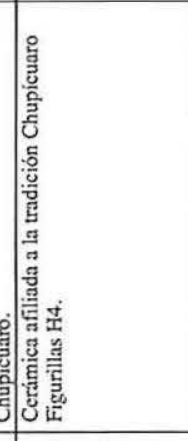 & 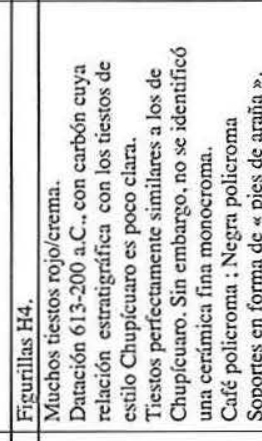 & 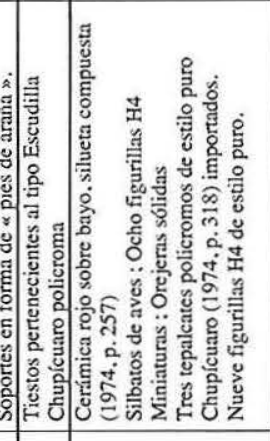 & 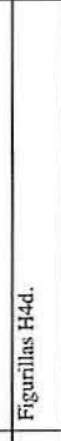 \\
\hline 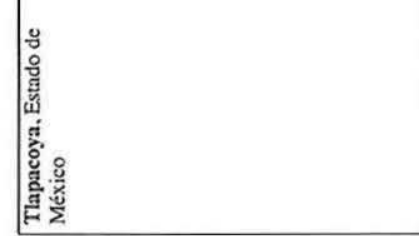 & 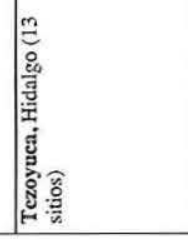 & 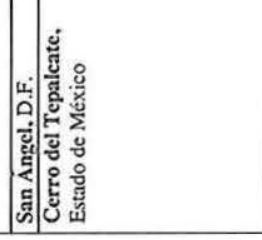 & 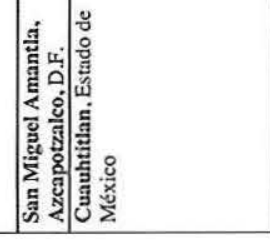 & 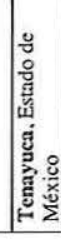 \\
\hline
\end{tabular}




\begin{tabular}{|c|c|c|c|c|c|c|c|c|c|c|c|c|c|}
\hline 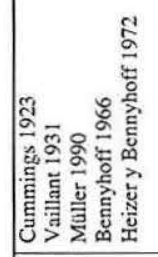 & 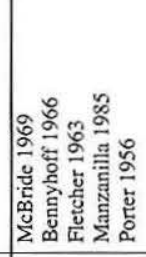 & 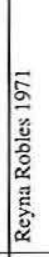 & 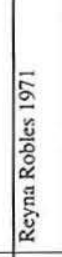 & 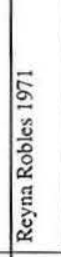 & 过 & 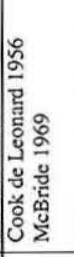 & 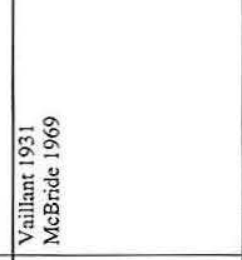 & 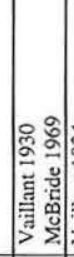 & 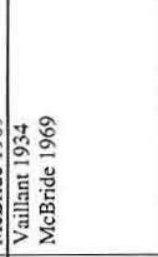 & 总 & 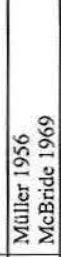 & 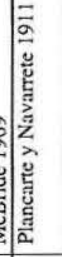 & 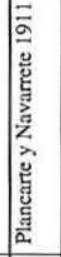 \\
\hline is & in & in & is & is & in &. & $\vec{n}$ & in & in & . & . & . & . \\
\hline 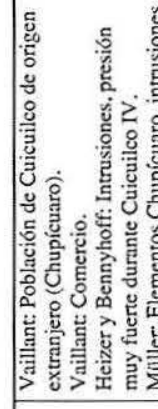 & 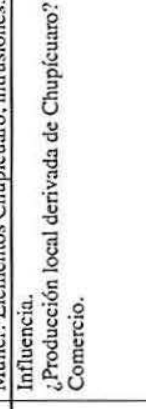 &. & . & . &. & 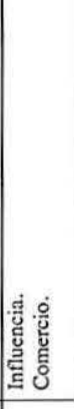 & 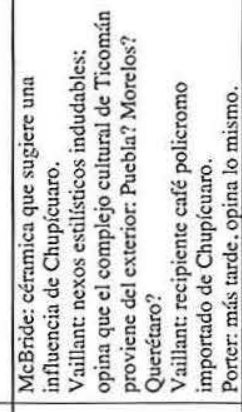 & 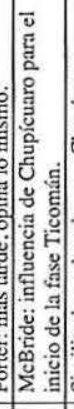 & 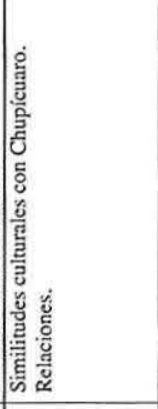 & 总 & 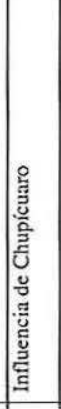 & . & \\
\hline 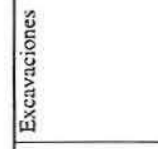 & 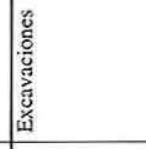 &. & . & . & 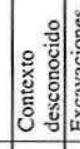 & & 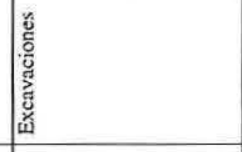 & 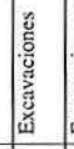 & 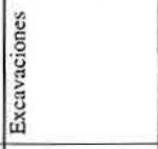 & 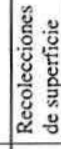 & & & 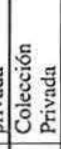 \\
\hline 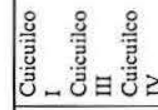 & 总蒡 & 遌. & 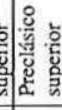 & & 1 & & 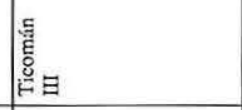 & 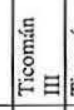 & 趌 & . & 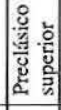 & 帘. & . \\
\hline 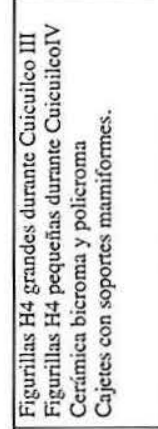 & 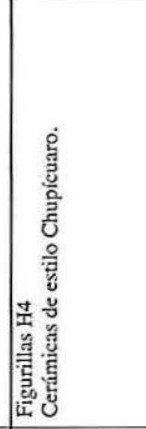 & 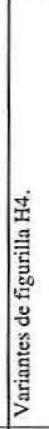 & 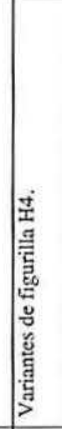 & 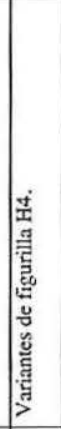 & 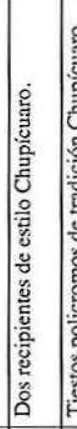 & 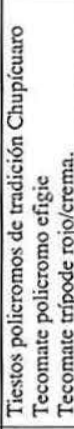 & 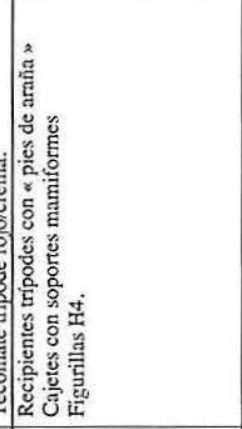 & 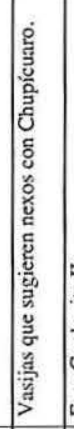 & 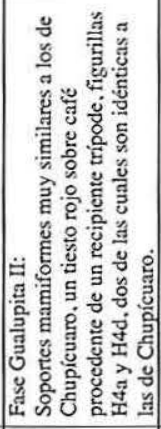 & 要 & 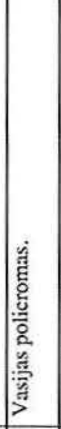 & 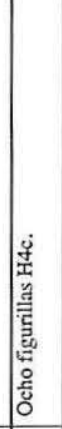 & 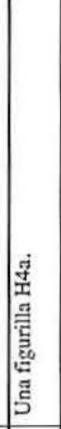 \\
\hline 造 & 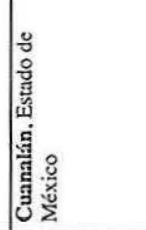 & 崖 & 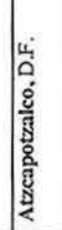 & 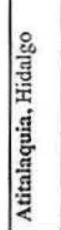 & 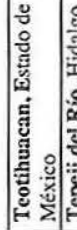 & 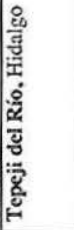 & 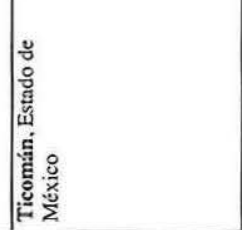 & . & & 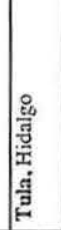 & 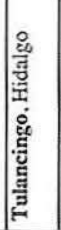 & 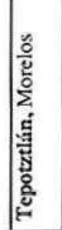 & Uू. \\
\hline
\end{tabular}

